NBER WORKING PAPER SERIES

\title{
INTERNATIONAL CAPITAL FLOWS UNDER DISPERSED INFORMATION: THEORY AND EVIDENCE
}

\author{
Cédric Tille \\ Eric van Wincoop \\ Working Paper 14390 \\ http://www.nber.org/papers/w14390 \\ NATIONAL BUREAU OF ECONOMIC RESEARCH \\ 1050 Massachusetts Avenue \\ Cambridge, MA 02138 \\ October 2008
}

Cedric Tille gratefully acknowledges financial support from the Swiss National Science Foundation and the National Centre of Competence in Research "Financial Valuation and Risk Management" (NCCR FINRISK). van Wincoop gratefully acknowledges financial support from the National Science Foundation (grant SES-0649442), the Bankard Fund for Political Economy, the Hong Kong Institute for Monetary Research and the Netherlands Central Bank. We thank Philippe Bacchetta, Paul Bergin, Casper de Vries, Bernard Dumas, Robert Kollmann, Frank Warnock, participants at the CEPR Third Annual Conference on the Macroeconomics of Global Interdependence, the 2008 NBER summer institute, the 2008 meetings of the Society for Economic Dynamics and the European Economic Association, Cornell University, the IMF, the Federal Reserve Bank of New York, the Board of Governors of the Federal Reserve, the Netherlands Central Bank, Hong Kong Authority Authority, UC Davis and the University of Amsterdam for valuable discussions and comments on an earlier draft. We thank Simone Meier for valuable research assistance. The views expressed herein are those of the author(s) and do not necessarily reflect the views of the National Bureau of Economic Research.

NBER working papers are circulated for discussion and comment purposes. They have not been peerreviewed or been subject to the review by the NBER Board of Directors that accompanies official NBER publications.

(C) 2008 by Cédric Tille and Eric van Wincoop. All rights reserved. Short sections of text, not to exceed two paragraphs, may be quoted without explicit permission provided that full credit, including $\odot$ notice, is given to the source. 
International Capital Flows under Dispersed Information: Theory and Evidence

Cédric Tille and Eric van Wincoop

NBER Working Paper No. 14390

October 2008

JEL No. F32,F36,F41

\begin{abstract}
$\underline{\text { ABSTRACT }}$
We develop a new theory of international capital flows based on dispersed information across individual investors. There is extensive evidence of information heterogeneity within and across countries, which has proven critical to understanding asset price behavior. We introduce information dispersion into an open economy dynamic general equilibrium portfolio choice model, and emphasize two implications for capital flows that are specific to the presence of dispersed information. First, gross and net capital flows become partially disconnected from publicly observed fundamentals. Second, capital flows (particularly gross flows) contain information about future fundamentals, even after controlling for current fundamentals. We find that these implications are quantitatively significant and consistent with data for industrialized countries.
\end{abstract}

Cédric Tille

Graduate Institute for International and Development Studies

Department of Economics

University of Geneva

Pavillon Rigot, Avenue de la Paix 11 A

1202 Geneve, Switzerland

cedric.tille@graduateinstitute.ch

Eric van Wincoop

Department of Economics

University of Virginia

P.O. Box 400182

Charlottesville, VA 22904-4182

and NBER

vanwincoop@virginia.edu 


\section{Introduction}

The sharp increase in both gross and net international capital flows over the past two decades has lead to a renewed interest in understanding their driving forces. Until not long ago most models of international capital flows were ill-equipped to address these developments because they either limited international trade to a riskfree bond or assumed complete financial markets. A new literature has recently emerged to connect better with the empirical evidence through the development of models that introduce portfolio choice into open economy DSGE environments. ${ }^{1}$ These models shed light on both net and gross capital flows (capital inflows and outflows), and emphasize the role of time-varying risk and expected returns in driving capital flows.

While these models represent substantial progress, they remain significantly at odds with the data in one key respect. They assume that all agents have exactly the same information, and therefore the same expected returns and perceived risk. This is a major limitation for two reasons. First, there is extensive evidence on the heterogeneity of information across investors. Most directly, survey evidence shows that expectations about future macro fundamentals and asset prices differ widely across financial institutions and individuals. A substantial literature has also documented information differences across countries, with local investors having more reliable information than foreign investors. ${ }^{2}$ Second, this heterogeneity plays a central role in driving asset prices. Many features, such as the close link between exchange rates and cumulative order flow documented by Evans and Lyons (2002), can only be understood in the presence of dispersed information. The large market microstructure literature in finance has emphasized the implications of information heterogeneity for asset prices and trading volume. ${ }^{3}$

The contribution of this paper is twofold. First, we develop a general equilibrium theory of international capital flows under dispersed information that integrates key elements of the market microstructure literature in finance and the

\footnotetext{
${ }^{1}$ Devereux and Sutherland (2007), Tille and van Wincoop (2008) and Evans and Hnatkovska (2008) have developed tractable methods for solving such models.

${ }^{2}$ See for example Bae, Stulz and Tan (2007), who document that earnings forecasts are more precise for local than foreign analysts. Section 2 of that paper provides a review of the evidence on information asymmetries across countries. There is also evidence that agency problems are better monitored by locals, e.g. Leuz, Lins and Warnock (2008).

${ }^{3}$ See Brunnermeier (2001) for a nice review of the literature.
} 
DSGE literature in macroeconomics. We adopt the two key features of noisy rational expectations (NRE) models from the market microstructure literature. First, agents have private information about future fundamentals. Second, there is "noise" in the form of unobserved portfolio shifts, which prevent asset prices from fully revealing the private information. We integrate these features into a two-country DSGE model where agents make decisions about portfolio allocation, physical investment and saving.

Our second contribution is to confront the main implications of the theory to the data. In the absence of private information capital flows are entirely driven by publicly observed fundamentals (e.g. GDP growth, the budget deficit, inflation). ${ }^{4}$ In our model capital flows are also driven by private information as it affects expectations of asset payoffs and portfolio allocation. This leads to two implications that we confront to the data. First, capital flows are partially disconnected from current publicly observed fundamentals. Second, capital flows help forecast future fundamentals, even after controlling for their current values. This reflects the role of private information about future fundamentals. We confirm the quantitative relevance of these implications through a calibration of the model. We also show that these implications are consistent with data on aggregate capital flows for industrialized countries.

Figure 1 provides the essence of the theoretical contribution. The model contains four ingredients: information dispersion, portfolio choice, non-linearity and general equilibrium structure. Standard macro DSGE models only contain the last two ingredients. The recent contributions introducing portfolio choice in DSGE models include the last three ingredients, but not the first one. By contrast, the models in the market microstructure literature in finance only contain the first two ingredients. In particular, NRE models are not general equilibrium frameworks, as they assume that there is an infinite supply of an asset with a constant riskfree return. ${ }^{5}$ Moreover, they are entirely linear. While these aspects of NRE models facilitate their solution, they do not fit well with the open economy DSGE setups within which the literature on international capital flows is framed.

\footnotetext{
${ }^{4}$ This also includes public news variables that are featured in the literature on the impact of news shocks, such as Beaudry and Portier (2003), Devereux and Engel (2006), Jaimovich and Rebelo (2008) and Lorenzoni (2007).

${ }^{5}$ Even when assets with a riskfree return exist (e.g. Treasury bonds), in a general equilibrium framework the demand for such assets must equate their finite supply.
} 
We also make a methodological contribution by solving a DSGE model with portfolio choice and information dispersion. We cannot directly rely on the recently developed approximation methods for solving DSGE models with portfolio choice, as they abstract from information dispersion. Neither can we directly apply the standard methods for solving NRE models because of the linear, partial equilibrium, nature of these models. We develop a solution that extends the approximation methods used for solving DSGE models to encompass the key elements from the method used for solving NRE models. Even though the combined presence of DSGE and NRE features makes the model quite rich, we are nonetheless able to obtain an analytical solution. This facilitates transparency of the results.

The paper is related to a small set of papers that have introduced NRE asset pricing features into open economy models. These include Albuquerque, Bauer and Schneider (2007,2008), Bacchetta and van Wincoop (2004,2006), Brennan and Cao (1997), Gehrig (1993) and Veldkamp and van Nieuwerburgh (2008). These papers focus on a variety of issues, ranging from exchange rate puzzles to international portfolio home bias and the relationship between asset returns and portfolio flows. Together they show that information dispersion within and across countries can tell us a lot about a wide range of stylized facts related to international asset prices and portfolio allocation. However, none of these papers have implications for aggregate capital inflows and outflows or even net capital flows (the current account). This is not just because the focus is on other questions but more fundamentally because these are not true general equilibrium models due to the presence of a riskfree asset that is in infinite supply.

The paper is organized as follows. Section 2 describes the model. The solution method is discussed in section 3. Section 4 derives implications for asset prices, portfolio allocation and capital flows. This leads to two testable implications that are confronted to the data in section 5. Section 6 concludes.

\section{The Model}

There are two countries, Home and Foreign, with a unit mass of atomistic agents in each country. Both countries produce the same good using labor and capital. The good can be used for consumption or investment, the latter entailing an adjustment cost. We adopt a standard overlapping generation setup with agents living two 
periods. Young agents earn labor income and make consumption and portfolio decisions. They can invest in claims on capital in both countries. While these are claims on aggregate capital rather than residual claims, we refer to them as Home and Foreign equity for convenience. Old agents consume the return on their investment.

\subsection{Production, Investment and Assets}

The consumption good is taken as the numeraire. It is produced in both countries using a constant returns to scale technology in labor and capital:

$$
Y_{i, t}=A_{i, t} K_{i, t}^{1-\omega} N_{i, t}^{\omega} \quad i=H, F
$$

where $H$ and $F$ denote the Home and Foreign country respectively. $Y_{i}$ is the output in country $i, A_{i}$ is a country-specific exogenous stochastic productivity term, $K_{i}$ is the capital input and $N_{i}$ the labor input that we normalize to unity. Log productivity follows an autoregressive process:

$$
a_{i, t+1}=\rho a_{i, t}+\varepsilon_{i, t+1} \quad i=H, F
$$

where $\varepsilon_{i, t+1}$ has a $N\left(0, \sigma_{a}^{2}\right)$ distribution and is uncorrelated across countries.

The dynamics of the capital stock reflects depreciation at a rate $\delta$ and investment $I_{i, t}$ :

$$
K_{i, t+1}=(1-\delta) K_{i, t}+I_{i, t} \quad i=H, F
$$

A share $\omega$ of output is paid to labor, with the remaining going to capital. The wage rate in country $i$ is then

$$
W_{i, t}=\omega A_{i, t}\left(K_{i, t}\right)^{1-\omega} \quad i=H, F
$$

Capital is supplied by a competitive installment firm. In period $t$ the installment firm produces $I_{i, t}$ units of new capital and sells them at a price $Q_{i, t}$ that the firm takes as given. The production of $I_{i, t}$ units of capital good requires purchasing $I_{i, t}$ units of the consumption good and incurring a quadratic adjustment cost, so the total cost in units of the consumption good is:

$$
I_{i, t}+\frac{\xi}{2} \frac{\left(I_{i, t}-\delta K_{i, t}\right)^{2}}{K_{i, t}}
$$


The profit of installing $I_{i, t}$ units of capital in country $i$ is then $Q_{i, t} I_{i, t}$ minus the cost (4). Profit maximization by the installment firm implies a standard Tobin's $\mathrm{Q}$ relation:

$$
\frac{I_{i, t}}{K_{i, t}}=\delta+\frac{Q_{i, t}-1}{\xi}
$$

A unit of Home equity is a claim on a unit of Home capital. The equity price is equal to the cost of purchasing one unit of capital from the installment firm, $Q_{H, t}$. An investor purchasing a unit of Home equity at the end of period $t$ gets a dividend of $(1-\omega) Y_{H, t+1} / K_{H, t+1}$ in period $t+1$, and can sell the remaining $1-\delta$ units of equity at a price $Q_{H, t+1}$. The returns on Home and Foreign equity are then

$$
\begin{aligned}
& R_{H, t+1}=\frac{(1-\omega) A_{H, t+1}\left(K_{H, t+1}\right)^{-\omega}+(1-\delta) Q_{H, t+1}}{Q_{H, t}} \\
& R_{F, t+1}=\frac{(1-\omega) A_{F, t+1}\left(K_{F, t+1}\right)^{-\omega}+(1-\delta) Q_{F, t+1}}{Q_{F, t}}
\end{aligned}
$$

\subsection{Private Information and Noise}

We import the two key elements of NRE models: private information about future fundamentals and noise that prevents asset prices from completely revealing the private information. We introduce these elements to the model as follows.

\section{Private Information}

Each agent receives private signals about next period's productivity innovations in both countries. The signals observed by Home investor $j$ about respectively the $\log$ of Home and Foreign productivity are:

$$
\begin{aligned}
v_{j, t}^{H, H} & =\varepsilon_{H, t+1}+\epsilon_{j, t}^{H, H} & & \epsilon_{j, t}^{H, H} \sim N\left(0, \sigma_{H H}^{2}\right) \\
v_{j, t}^{H, F} & =\varepsilon_{F, t+1}+\epsilon_{j, t}^{H, F} & & \epsilon_{j, t}^{H, F} \sim N\left(0, \sigma_{H F}^{2}\right)
\end{aligned}
$$

Each signal consists of the true innovation and a stochastic error. Similarly, agent $j$ in the Foreign country observes the signals:

$$
\begin{aligned}
v_{j, t}^{F, H} & =\varepsilon_{H, t+1}+\epsilon_{j, t}^{F, H} & & \epsilon_{j, t}^{F, H} \sim N\left(0, \sigma_{H F}^{2}\right) \\
v_{j, t}^{F, F} & =\varepsilon_{F, t+1}+\epsilon_{j, t}^{F, F} & & \epsilon_{j, t}^{F, F} \sim N\left(0, \sigma_{H H}^{2}\right)
\end{aligned}
$$

As is standard in NRE models, we assume that the errors of the signals average to zero across investors in a given country $\left(\int_{0}^{1} \epsilon_{j, t}^{H, H} d j=\int_{0}^{1} \epsilon_{j, t}^{H, F} d j=0\right)$. 
Our setup is symmetric as the variance of signals on domestic productivity is the same for agents in the two countries, and so is the variance of signals on productivity abroad. We allow for an information asymmetry with agents receiving more precise signals about shocks in their own country than abroad: $\sigma_{H H}^{2} \leq \sigma_{H F}^{2}$.

\section{Noise}

Noise takes the form of unobserved portfolio shifts between assets for reasons unrelated to expected returns. In the NRE literature the noise is usually simply introduced exogenously in the form of noise trade or liquidity trade. Some papers have introduced it endogenously in various forms of hedge trade and liquidity trade. ${ }^{6}$ For our purposes the existence of a source of noise is more important than the exact nature of it.

We introduce the noise through a time-varying cost of investing abroad. A Home agent $j$ investing in the Foreign country receives the return (7) times an iceberg cost $e^{-\tau_{H j, t}}<1$. Similarly, a Foreign agent $j$ investing in the Home country receives the return (6) times an iceberg cost $e^{-\tau_{F j, t}}<1$. The cost of investment abroad does not represent a loss in resources but is instead a fee paid to brokers from the investor's country.

This cost of investing abroad fluctuates around a level $\tau$ that is the same for all investors. The average cost $\tau$ generates portfolio home bias in the steady state of the model, with agents tilting their holdings toward domestic assets. There are two reasons for introducing portfolio home bias. First, it is a well known feature of the data. Second, we will see that the impact of information dispersion on capital flows depends on the extent of portfolio home bias.

Fluctations around $\tau$ include both agent-specific and country-specific components. The costs faced by Home investors in period $t$ are distributed around an average value $\tau_{H, t}=\tau\left(1+\varepsilon_{t}^{\tau}\right)$, where $\varepsilon_{t}^{\tau}$ has a $N\left(0, \theta \sigma_{a}^{2}\right)$ distribution. This average cost $\tau_{H, t}$ is unobserved. An individual investor making a portfolio decision at time $t$ knows her own cost $\tau_{H j, t}$, but we assume that this individual cost is an infinitely noisy signal of the average cost. This assumption can be relaxed but simplifies the analysis. ${ }^{7}$ The average cost in the Foreign country is $\tau_{F, t}=\tau\left(1-\varepsilon_{t}^{\tau}\right)$, which is also unobserved. For simplicity, our specification implies that the average

\footnotetext{
${ }^{6}$ See for example Bacchetta and van Wincoop (2006), Dow and Gorton (1995), Spiegel and Subrahmanyam (1992) and Wang (1994).

${ }^{7}$ See Bacchetta and van Wincoop (2006) for a similar assumption.
} 
of $\tau_{H, t}$ and $\tau_{F, t}$ is constant, and focuses on movements in the relative cost between the two countries. For instance, an increase in $\tau_{t}^{D}=\tau_{H, t}-\tau_{F, t}=2 \tau \varepsilon_{t}^{\tau}$ leads to a portfolio shift towards Home equity, as it is relatively more expensive for Home investors to invest abroad than for Foreign investors. Such unobserved portfolio shifts prevent the relative equity price from revealing private information.

\subsection{Consumption and Portfolio Choice}

Our assumption of an overlapping generation structure simplifies the model in two ways. First, it removes the well-known pitfall in open economy models that temporary income shocks can have a permanent effect on the distribution of wealth across countries when agents have infinite lives. The finite life assumption of OLG models leads to a stationary distribution of wealth. Second, investors have only a one period investment horizon and therefore do not face the issue of hedging against changes in future expected returns.

A young Home agent $j$ at time $t$ chooses her consumption and portfolio to maximize

$$
\frac{\left(C_{y, t}^{H j}\right)^{1-\gamma}}{1-\gamma}+\beta E_{t}^{H j} \frac{\left(C_{o, t+1}^{H j}\right)^{1-\gamma}}{1-\gamma}
$$

where $C_{y, t}$ is consumption when young and $C_{o, t+1}$ is consumption when old. We assume $\gamma>1$. Agent $j$ maximizes (12) subject to the budget constraint and portfolio return, $R_{t+1}^{p, H j}$ :

$$
\begin{aligned}
& C_{o, t+1}^{H j}=\left(W_{H, t}-C_{y, t}^{H j}\right) R_{t+1}^{p, H j} \\
& R_{t+1}^{p, H j}=z_{H j, t} R_{H, t+1}+\left(1-z_{H j, t}\right) e^{-\tau_{H j, t}} R_{F, t+1}
\end{aligned}
$$

where $z_{H j, t}$ is the fraction of wealth invested in Home equity.

The first-order conditions for consumption and portfolio choice are:

$$
\begin{aligned}
& \left(C_{y, t}^{H j}\right)^{-\gamma}=\beta\left(W_{H, t}-C_{y, t}^{H j}\right)^{-\gamma} E_{t}^{H j}\left(R_{t+1}^{p, H j}\right)^{1-\gamma} \\
& E_{t}^{H j}\left(R_{t+1}^{p, H j}\right)^{-\gamma}\left(R_{H, t+1}-R_{F, t+1} e^{-\tau_{H j, t}}\right)=0
\end{aligned}
$$

(14) is the consumption Euler equation that links the marginal utility of current consumption with the expected marginal utility of future consumption, including the rate of return. (15) is the portfolio Euler equation that equates the expected 
discounted return (the expected product of the asset pricing kernel and asset returns) across assets. The asset pricing kernel is the marginal utility of future consumption, which is proportional to the return on the agent's portfolio. A central aspect of our model is that (14)-(15) are evaluated with expectations that can differ across individual agents.

Foreign agents face an analogous decision problem with portfolio return

$$
R_{t+1}^{p, F j}=z_{F j, t} e^{-\tau_{F j, t}} R_{H, t+1}+\left(1-z_{F j, t}\right) R_{F, t+1}
$$

The corresponding optimality conditions for a Foreign investor $j$ are:

$$
\begin{aligned}
& \left(C_{y, t}^{F j}\right)^{-\gamma}=\beta\left(W_{F, t}-C_{y, t}^{F j}\right)^{-\gamma} E_{t}^{F j}\left(R_{t+1}^{p, F j}\right)^{1-\gamma} \\
& E_{t}^{F j}\left(R_{t+1}^{p, F j}\right)^{-\gamma}\left(R_{H, t+1} e^{-\tau_{F j, t}}-R_{F, t+1}\right)=0
\end{aligned}
$$

The average portfolio shares invested by Home and Foreign investors in Home equity are denoted $z_{H, t}=\int_{0}^{1} z_{H j, t} d j$ and $z_{F, t}=\int_{0}^{1} z_{F j, t} d j$.

\subsection{Asset and Goods Market Clearing}

We assume that the brokers who receive the fees on investment abroad fully consume it. Owners of the installment firms also consume profits each period. The goods market equilibrium condition is:

$$
\begin{aligned}
& Y_{H, t+1}+Y_{F, t+1}=Q_{H, t+1} I_{H, t+1}+Q_{F, t+1} I_{F, t+1}+\int_{0}^{1} C_{y, t+1}^{H j} d j+\int_{0}^{1} C_{y, t+1}^{F j} d j \\
& +\int_{0}^{1}\left(W_{H, t}-C_{y, t}^{H j}\right)\left(z_{H j, t} R_{H, t+1}+\left(1-z_{H j, t}\right) R_{F, t+1}\right) d j \\
& +\int_{0}^{1}\left(W_{F, t}-C_{y, t}^{F j}\right)\left(z_{F j, t} R_{H, t+1}+\left(1-z_{F j, t}\right) R_{F, t+1}\right) d j
\end{aligned}
$$

The left hand side is world output. The first two terms on the right hand side represent investment. ${ }^{8}$ The next two terms represent consumption by young agents. The final two terms represent consumption by old agents and the brokers. ${ }^{9}$

\footnotetext{
${ }^{8}$ The installation cost does not enter. On the one hand it raises demand for the good (from the installation process itself). On the other hand it reduces profits, and therefore consumption, of the owners of installment firms.

${ }^{9}$ The cost of investing abroad does not enter, as the income of the brokers exactly offsets the cost for old agents.
} 
Asset market clearing requires that the value of capital in a country is equal to the value of holdings of the country's equity by young agents. The financial wealth of respectively a Home and Foreign agent $j$ is $W_{H t}-C_{y, t}^{H j}$ and $W_{F t}-C_{y, t}^{F j}$. The asset market clearing conditions are then

$$
\begin{aligned}
Q_{H, t} K_{H, t+1}= & \int_{0}^{1}\left(W_{H t}-C_{y, t}^{H j}\right) z_{H j, t} d j+\int_{0}^{1}\left(W_{F t}-C_{y, t}^{F j}\right) z_{F j, t} d j \\
Q_{F, t} K_{F, t+1}= & \int_{0}^{1}\left(W_{H t}-C_{y, t}^{H j}\right)\left(1-z_{H j, t}\right) d j+ \\
& \int_{0}^{1}\left(W_{F t}-C_{y, t}^{F j}\right)\left(1-z_{F j, t}\right) d j
\end{aligned}
$$

\section{Solution Method}

The solution combines and extends methods for solving standard NRE models with a recently developed local approximation methods for solving DSGE models with portfolio choice. NRE models are usually solved in three steps. The first step involves a conjecture for the equilibrium asset price. The second step computes the expectation of future asset payoffs by solving a signal extraction problem that uses public and private information as well as information from the equilibrium asset price. The last step invokes asset market equilibrium. The main difficulty here will be in the last step as we need to impose not just asset market equilibrium but the complete general equilibrium of the model in a highly non-linear environment.

We handle the last step by extending the local approximation method recently developed by Devereux and Sutherland (2007) and Tille and van Wincoop (2008) for DSGE models with portfolio choice. The method iteratively solves for the various components of the variables. A variable $x_{t}$ can be decomposed into its components of all orders. The zero-order component, denoted $x(0)$, is the level of $x_{t}$ when $\sigma_{a} \rightarrow 0$. The first-order component $x_{t}(1)$ is linear in model innovations, or in the standard deviation $\sigma_{a}$ of model innovations. Higher orders are defined analogously.

We discuss each of these three steps in broad terms. The algebra is described further in the Appendix, with complete details left to a Technical Appendix that is available on request. We use lower case letters for logs and superscripts A and $\mathrm{D}$ to denote respectively the average and difference of a variable across the two countries $\left(x^{D}=x_{H}-x_{F}, x^{A}=\left(x_{H}+x_{F}\right) / 2\right)$. 


\subsection{Asset Price Conjecture}

Only the relative equity price is affected by private information. The average equity price is driven by global asset demand and therefore global saving, which is not affected by private information. We make the following conjecture for the relative $\log$ equity price $q_{t}^{D}=q_{H, t}-q_{F, t}$ :

$$
q_{t}^{D}=f\left(S_{t}, x_{t}^{D}\right)
$$

where

$$
S_{t}=\left(a_{t}^{D}, a_{t}^{A}, k_{t}^{D}, k_{t}^{A}\right)
$$

is the vector of publicly observed state variables and

$$
x_{t}^{D}=\varepsilon_{t+1}^{D}+\lambda \tau_{t}^{D} / \tau
$$

depends on the unobserved state variables $\varepsilon_{t+1}^{D}$ and $\tau_{t}^{D}$. Since we adopt a local approximation method, described below, the conjecture (21) is verified locally up to quadratic terms in observed and unobserved state variables.

The logic behind this conjecture is as follows. As in any DSGE model, the solution for control variables (including asset prices) will be a function of state variables. Usually these state variables are publicly observed. In our model this is the case for the variables $S_{t}$. However, there are now also unobserved state variables, on which agents get noisy signals. We conjecture that the unobserved state variables jointly affect the asset price through $x_{t}^{D}$. The relative future productivity innovation $\varepsilon_{t+1}^{D}$ should affect the relative asset price through private information. The relative asset price should depend on $\tau_{t}^{D}$ as time variation in this relative friction leads to portfolio shifts between Home and Foreign equity.

\subsection{Signal Extraction}

This conjecture significantly simplifies signal extraction. While the function $f($. will be non-linear in $x_{t}^{D}$, two aspects make simple linear signal extraction feasible. First, we have conjectured (and will verify) that the relative asset price depends on a variable $x_{t}^{D}$ that is linear in the unknowns $\varepsilon_{t+1}^{D}$ and $\tau_{t}^{D}$. Second, locally $q_{t}^{D}$ will depend on $x_{t}^{D}$ with a positive slope. This means that we can extract $x_{t}^{D}$ from knowledge of the relative asset price $q_{t}^{D}$ and the publicly observed state space $S_{t}$. 
The asset price signal therefore translates into a signal that is linear in the future fundamental $\epsilon_{t+1}^{D}$ and the "noise" $\tau_{t}^{D}$.

We then have three linear signals about next period's technology innovations: (i) the price signal, which tells us the level of $\varepsilon_{t+1}^{D}+\lambda \tau_{t}^{D} / \tau$ from (23), (ii) the private signals (8)-(11) and (iii) the public signals that $\varepsilon_{H, t+1}$ and $\varepsilon_{F, t+1}$ are drawn from independent $N\left(0, \sigma_{a}^{2}\right)$ distributions. We solve this signal extraction problem in Appendix B. It gives conditional normal distributions of $\varepsilon_{H, t+1}$ and $\varepsilon_{F, t+1}$ that vary across agents. The expectation of future productivity innovations by agent $j$ in the Home country takes the form

$$
E_{t}^{H, j}\left|\begin{array}{c}
\varepsilon_{H, t+1} \\
\varepsilon_{F, t+1}
\end{array}\right|=\left|\begin{array}{c}
\alpha_{\varepsilon H, x D}^{H j} x_{t}^{D}+\alpha_{\varepsilon H, v H}^{H j} v_{j, t}^{H, H}+\alpha_{\varepsilon H, v F}^{H j} v_{j, t}^{H, F} \\
\alpha_{\varepsilon F, x D}^{H j} x_{t}^{D}+\alpha_{\varepsilon F, v H}^{H j} v_{j, t}^{H, H}+\alpha_{\varepsilon F, v F}^{H j} v_{j, t}^{H, F}
\end{array}\right|
$$

All coefficients are defined in Appendix B. The average expectation across Home agents, denoted by $\bar{E}_{t}^{H}$, is:

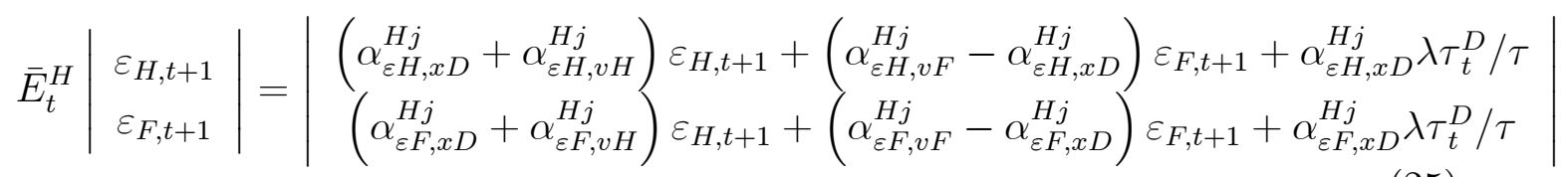

where we used (8)-(11) and (23). Analogous results apply to Foreign agents. Average expectations of future productivity therefore depend on future productivity levels themselves and on the noise $\tau_{t}^{D}$. Through rational confusion an increases in $\tau_{t}^{D}$ raises the expectation of $\varepsilon_{t+1}^{D}$. This is because a rise in $\tau_{t}^{D}$ leads to a higher relative price of Home equity, which agents use as a signal of future relative productivity.

\subsection{General Equilibrium}

The final step in the solution of NRE models involves imposing asset market equilibrium. In a DSGE model this step is more involved since we will need to invoke the full general equilibrium of the model, including multiple asset market and goods market clearing conditions and Euler equations for portfolio choice and consumption. Moreover, we need to do so in a highly non-linear environment.

We adopt and extend the local approximation method for DSGE models with portfolio choice developed by Devereux and Sutherland (2007) and Tille and van Wincoop (2008), from hereon DS and TvW. It provides an exact solution to the 
zero, first and second-order components of control and state variables. The only exception is $z_{t}^{D}=z_{H, t}-z_{F, t}$, for which the method delivers the zero and first-order components.

The method distinguishes between the difference across countries in portfolio Euler equations and all "other equations" and similarly between the difference $z_{t}^{D}$ across countries in portfolio allocation and all "other variables". It first solves for the zero-order component of $z_{t}^{D}$ and the first-order component of the "other variables" by jointly imposing the second-order component of the difference across countries in portfolio Euler equations and the first-order component of the "other equations". This step is subsequently repeated one order higher for all equations and variables in order to obtain the first-order component of $z_{t}^{D}$ jointly with the second-order component of all "other variables". We refer to DS and TvW for detailed descriptions of the method.

In implementing and extending the method to our model, three issues need to be addressed that are specific to the introduction of information dispersion. These involve the order component of the errors of the private signals, the computation of expectations of equations and the computation of the parameter $\lambda$ that captures the noise to signal ratio in the relative asset price in equation (23).

\section{Errors in Private Signals}

We assume that $\sigma_{H H}^{2}$ and $\sigma_{H F}^{2}$ are zero-order. It is important to distinguish between the volatility of the innovations in the model, captured by $\sigma_{a}^{2}$, and the uncertainty of the private signals about these innovations, captured by $\sigma_{H H}^{2}$ and $\sigma_{H F}^{2}$. We keep these two dimensions distinct. A reduction in the volatility of innovations is then not accompanied by an increased precision of the signals on the innovations.

This assumption implies that the private signals (8)-(11) entail a zero-order component (the errors of the signals) and a first-order component (the true future productivity innovations). In Appendix B we show that it implies that the coefficients on the private signals in (24), $\alpha_{\varepsilon H, v H}^{H j}, \alpha_{\varepsilon H, v F}^{H j}, \alpha_{\varepsilon F, v H}^{H j}, \alpha_{\varepsilon F, v F}^{H j}$, are of order two. Differences in expected returns across individual investors are then second order, as they combine these second-order coefficients with the zero-order errors of the private signals in (8)-(11). The differences in expected returns being small, of order two or higher, ensures that the cross-sectional distribution of portfolio shares does not explode when risk becomes small. This is because expected returns are 
divided by the variance of the excess return in the optimal portfolios. If errors in private signals were first-order, differences in expectations would be first-order as well and the distribution of portfolio shares would explode for low levels of risk. For the same reason we assume that the average cost $\tau$ of investment abroad is second-order.

\section{Computing Expectations}

Consider the expected value of a term eq, which consists of one or several variables, $E$ eq. In common knowledge models, computing the second-order component of this expectation simply entails taking the expectation of the second-order component of $e q$, so that $[E e q](2)=E[e q(2)]$. This is no longer the case here though, ${ }^{10}$ and we need to be careful to first compute expectations of equations before splitting them into components of different orders. To compute expectations of equations, both the equations and the solution of control variables need to be in polynomial form. It is sufficient to use an $o$-order polynomial approximation when the goal is to compute the $o$-order component of an equation or variable.

Equations are written as polynomials in $S_{t}, x_{t}^{D}, x_{t+1}^{D}$ and $\varepsilon_{t+1}=\left(\varepsilon_{H, t+1}, \varepsilon_{F, t+1}\right)^{\prime}$. Control variables are conjectured as polynomial solutions in the observed and unobserved state variables $S_{t}$ and $x_{t}^{D}$. A quadratic polynomial conjecture for the control variables is sufficient as we will only solve zero, first and second-order components of control variables. We therefore conjecture (for $h=D, A)^{11}$

$$
\begin{aligned}
q_{t}^{h} & =\alpha_{q h} S_{t}+\alpha_{5, q h} x_{t}^{D}+S_{t}^{\prime} A_{q h} S_{t}+\beta_{q h} S_{t} x_{t}^{D}+\mu_{q h}\left(x_{t}^{D}\right)^{2}+\kappa_{q h} \\
c_{y t}^{h} & =\alpha_{c h} S_{t}+\alpha_{5, c h} x_{t}^{D}+S_{t}^{\prime} A_{c h} S_{t}+\beta_{c h} S_{t} x_{t}^{D}+\mu_{c h}\left(x_{t}^{D}\right)^{2}+\kappa_{c h} \\
k_{t+1}^{h} & =\alpha_{k h} S_{t}+\alpha_{5, k h} x_{t}^{D}+S_{t}^{\prime} A_{k h} S_{t}+\beta_{k h} S_{t} x_{t}^{D}+\mu_{k h}\left(x_{t}^{D}\right)^{2}+\kappa_{k h}
\end{aligned}
$$

Expectations of equations are computed using the results from signal extraction. Invoking the order components of equations as in DS and TvW will then give the zero and first-order components of the parameters $\alpha$ (with various subscripts) in (26)-(28) and the zero-order component of all the other parameters.

\footnotetext{
${ }^{10}$ As an example, $\varepsilon_{H, t+1}(2)=0$, so that $E_{t}\left[\varepsilon_{H, t+1}(2)\right]=0$. But $E_{t}\left(\varepsilon_{H, t+1}\right)$ has a non-zero second-order component as the weight attached to private signals is of order two and higher.

${ }^{11}$ No conjectures will be needed for $z_{t}^{D}$ and $z_{t}^{A}$. After all "other variables" are solved up to second order, $z_{t}^{D}(1)$ follows from the third-order component of the difference in portfolio Euler equations and $z_{t}^{A}(1), z_{t}^{A}(2)$ follow from the first and second-order components of the difference of the asset market clearing conditions.
} 


\section{Computing $\lambda$}

In NRE models the signal to noise ratio $\lambda$ in (23) can be solved by imposing asset market equilibrium. A version of that applies here as well. We need to impose the difference between the two asset market clearing conditions (19)-(20). This relates the average share invested in Home equity, $z_{t}^{A}$, to the share of Home equity supply. Combining the first-order components of (26)-(28) with that of (19)-(20) solves $z_{t}^{A}(1)$ by equating it to the first-order component from the supply side. In order to actually impose market equilibrium we need to compute $z_{t}^{A}(1)$ from a portfolio or demand perspective as well. This is done by using the thirdorder component of the average of the Euler equations for portfolio choice, (15) and (18). Equating $z_{t}^{A}(1)$ from the demand side to the Home equity share from the supply side yields a solution for $\lambda$, as shown in Appendix C.

\section{Asset Prices, Portfolio Allocation and Capital Flows}

In this section we discuss the first-order solution of asset prices, optimal portfolio shares and capital flows.

\subsection{Asset Prices}

The first-order solution of the relative asset price is

$$
\begin{aligned}
q_{t}^{D}(1) & =\alpha_{q, D}(0) S_{t}(1)+\alpha_{5, q D}(0) x_{t}^{D}(1) \\
& =\alpha_{1, q D}(0) a_{t}^{D}+\alpha_{3, q D}(0) k_{t}^{D}(1)+\alpha_{5, q D}(0)\left(\varepsilon_{t+1}^{D}+\lambda \tau_{t}^{D}(3) / \tau\right)
\end{aligned}
$$

with all parameters positive. The relative asset price is therefore driven by both publicly observed state variables, $a_{t}^{D}$ and $k_{t}^{D}$, and by unobserved state variables $\varepsilon_{t+1}^{D}$ and $\tau_{t}^{D}$. Both of these unobserved state variables generate a disconnect between asset prices and publicly observed fundamentals, a fact that is widely documented.

In the absence of information dispersion the relative asset price would, to the first-order, be entirely determined by the publicly observed state variables $S_{t}$. This is because future productivity innovations cannot affect current equilibrium asset prices, and shocks to $\tau_{t}^{D}$ only have a third-order effect on asset prices. Recall that a rise in $\tau_{t}^{D}=2 \tau \varepsilon_{t}^{\tau}$ is third-order. This leads to a third-order increase in the 
expected excess return on Home equity. In order to clear financial markets there needs to be a third-order drop in the expected excess return on Home equity, which takes place through a third-order rise in the Home equity price.

At first it may seem surprising that $\tau_{t}^{D}$ and $\varepsilon_{t+1}^{D}$ have a first-order effect on asset prices when we introduce information dispersion. As discussed above, shocks to $\tau_{t}^{D}$ are third-order. (25) also shows that private information alone leads to third-order changes in average expectations about $\varepsilon_{t+1}^{D}$, as first-order innovations are combined with the second-order coefficients on private signals.

The first-order impact of $\tau_{t}^{D}$ and $\varepsilon_{t+1}^{D}$ in (29) reflects the role of the relative asset price as an information coordination mechanism. Imagine that agents ignored $q_{t}^{D}$ as a source of information. The impact of $\tau_{t}^{D}$ and $\varepsilon_{t+1}^{D}$ would then be third-order as discussed above. But because both are of the same order in their impact on the relative asset price, it would imply that the price contains much more precise information about $\varepsilon_{t+1}^{D}$ than the private signals. After all, in the private signals the error terms are much larger (zero-order) than the productivity innovations themselves (first-order). It is this feature that explains why in equilibrium the weight attached to the price signal in expectations of future productivity innovations is much larger (zero-order) than the weight attached to private signals (second-order).

The zero-order weight attached to the price signal implies that changes in $\tau_{t}^{D}$ and $\varepsilon_{t+1}^{D}$ have a first-order effect on the expectation of $\varepsilon_{H, t+1}$ and $\varepsilon_{F, t+1}$, which leads to a first-order effect on asset prices. ${ }^{12}$ It is through the information coordination role of the price signal that agents learn a lot more about $\varepsilon_{t+1}^{D}$, amplifying its impact from third to first-order. The impact of the noise $\tau_{t}^{D}$ is also amplified from third to first-order as it affects the expectation of future productivity innovations through the price signal (rational confusion). This amplified effect of the noise can make a huge difference. For example, Gennotte and Leland (1990) provide evidence that during the U.S. stock market crash of October 19, 1987, the impact of non-informational trade (noise) on the U.S. stock price was amplified by a factor greater than 100 as a result of the information content of the stock price.

\footnotetext{
${ }^{12}$ In (24) this take place through zero-order coefficients $\alpha_{\epsilon H, x D}^{H j}$ and $\alpha_{\epsilon F, x D}^{H j}$ that multiply $x_{t}^{D}$ in the expectations of future productivity innovations.
} 


\subsection{Portfolio Allocation}

We now discuss the implications of the model for portfolio allocation, a key determinant of international capital flows. We present the results in terms of the average portfolio share invested in Home equity, $z_{t}^{A}$, and the difference across countries in the portfolio share invested in Home equity, $z_{t}^{D}$, considering both their zero and first-order components.

In terms of zero-order components, the asset market clearing conditions (19)(20) imply that $z^{A}(0)=0.5$. The difference in zero-order portfolio shares, $z^{D}(0)$, which represents portfolio home bias, is computed from the second-order component of the difference in portfolio Euler equations (15) and (18), and reflects the mean level $\tau$ of international financial frictions:

$$
z^{D}(0)=\frac{2 \tau}{\gamma\left[E_{t}\left(e r_{t+1}\right)^{2}\right](2)}
$$

where $e r_{t+1}=r_{H, t+1}-r_{F, t+1}$ is the difference in log returns or excess return.

We obtain expressions for the first-order component of the average and difference in optimal portfolio shares from the third-order component of respectively the average and difference in portfolio Euler equations (15) and $(18)^{13}$ :

$$
\begin{aligned}
z_{t}^{A}(1)= & \frac{\tau_{t}^{D}(3)}{2 \gamma\left[E_{t}\left(e r_{t+1}\right)^{2}\right](2)}+\frac{\left[\bar{E}_{t}^{A} e r_{t+1}\right](3)}{\gamma\left[E_{t}\left(e r_{t+1}\right)^{2}\right](2)} \\
& -\frac{\gamma-1}{\gamma} \frac{\left[\operatorname{var}_{t}\left(r_{H t+1}\right)\right](3)-\left[\operatorname{var}_{t}\left(r_{F t+1}\right)\right](3)}{2\left[E_{t}\left(e r_{t+1}\right)^{2}\right](2)} \\
z_{t}^{D}(1)= & \frac{\left[\bar{E}_{t}^{H} e r_{t+1}\right](3)-\left[\bar{E}_{t}^{F} e r_{t+1}\right](3)}{\gamma\left[\operatorname{var}_{t}\left(e r_{t+1}\right)\right](2)}-z^{D}(0) \frac{\left[\operatorname{var}_{t}\left(e r_{t+1}\right)\right](3)}{\left[\operatorname{var}_{t}\left(e r_{t+1}\right)\right](2)}
\end{aligned}
$$

where $\bar{E}_{t}^{A}$ denotes the average expectation across agents from both countries and $\bar{E}_{t}^{h}$ the average expectations across agents from country $h(h=H, F)$.

The first-order component of $z_{t}^{A}$ is driven by three intuitive elements in (31). First, a rise in $\tau_{t}^{D}(3)$ leads to a portfolio shift towards Home equity as the cost of investment abroad rises for Home relative to Foreign investors. Second, a higher average expected excess return $e r_{t+1}$ on Home equity net of financial frictions also leads to a portfolio shift towards Home equity. The last term in (31) represents time-variation in second moments, which are captured by their third-order compo-

\footnotetext{
${ }^{13}$ See Appendix $\mathrm{C}$ and $\mathrm{D}$ and the Technical Appendix for full derivations.
} 
nents. ${ }^{14}$ A rise in the variance of the Home return relative to that of the Foreign equity return leads to a shift towards Foreign equity (assuming $\gamma>1$ ).

The expression (32) for the difference $z_{t}^{D}(1)$ in portfolio shares captures timevariation in portfolio home bias. It is driven by two factors. First, an increase in the expected excess return on Home equity by Home investors relative to Foreign investors will lead to increased home bias. Second, an increase in the variance of the excess return reduces home bias. There is a tradeoff between investing at home due to the friction $\tau$ and achieving the gains from portfolio diversification. A higher variance of the excess return makes diversification more attractive, reducing home bias.

In the Technical Appendix we show that these moments affecting $z_{t}^{D}(1)$ take the form:

$$
\begin{aligned}
& {\left[\bar{E}_{H, t} e r_{t+1}\right](3)-\left[\bar{E}_{F, t} e r_{t+1}\right](3)=\delta_{1} \sigma_{a}^{2}\left[\frac{1}{\sigma_{H H}^{2}}-\frac{1}{\sigma_{H F}^{2}}\right] \varepsilon_{t+1}^{A}} \\
& {\left[\operatorname{var}_{t}\left(e r_{t+1}\right)\right](3)=\delta_{2} \sigma_{a}^{2} S_{t}(1)}
\end{aligned}
$$

where the parameters $\delta_{i}$ are zero-order and follow from the first and second-order solutions of the "other variables". To understand (33), assume that $\sigma_{H H}^{2}<\sigma_{H F}^{2}$, so that agents have better quality signals about their domestic equity market. When productivity levels rise in both countries next period, agents from both countries expect that productivity in their own country will rise more because they have better quality information about their own productivity. As a result they both expect the return on their own country's equity to rise relative to that of the other country, which leads to increased portfolio home bias $\left(\delta_{1}>0\right)$. (34) implies that changes in the variance of the excess return over time are driven only by changes in publicly observed state variables. ${ }^{15}$

\subsection{International Capital Flows}

After some straightforward balance of payments accounting outlined in Appendix $\mathrm{E}$, and using the results on portfolio allocation discussed above, we obtain the

\footnotetext{
${ }^{14}$ See Tille and van Wincoop (2008) for a further discussion of this.

${ }^{15}$ Only the second and fourth elements of $\delta_{2}$ are non-zero, so that only global state variables affect the variance of the excess return.
} 
following expressions for capital outflows and inflows:

$$
\begin{aligned}
\text { outflows }_{t}(1)= & \left(1-z_{H}(0)\right) s_{t}^{H}(1)+\frac{z^{D}(0)}{2} \frac{\Delta\left[\operatorname{var}_{t}\left(e r_{t+1}\right)\right](3)}{\left[E_{t}\left(e r_{t+1}\right)^{2}\right](2)} \\
& -\frac{\Delta \bar{E}_{t}^{A} e r_{t+1}(3)^{I S}}{\gamma\left[E_{t}\left(e r_{t+1}\right)^{2}\right](2)}-\frac{1}{2} \frac{\Delta\left[\bar{E}_{t}^{H} e r_{t+1}\right](3)-\Delta\left[\bar{E}_{t}^{F} e r_{t+1}\right](3)}{\gamma\left[E_{t}\left(e r_{t+1}\right)^{2}\right](2)} \\
\text { inflows }_{t}(1)= & \left(1-z_{H}(0)\right) s_{t}^{F}(1)+\frac{z^{D}(0)}{2} \frac{\Delta\left[\operatorname{var}_{t}\left(e r_{t+1}\right)\right](3)}{\left[E_{t}\left(e r_{t+1}\right)^{2}\right](2)} \\
& +\frac{\Delta \bar{E}_{t}^{A} e r_{t+1}(3)^{I S}}{\gamma\left[E_{t}\left(e r_{t+1}\right)^{2}\right](2)}-\frac{1}{2} \frac{\Delta\left[\bar{E}_{t}^{H} e r_{t+1}\right](3)-\Delta\left[\bar{E}_{t}^{F} e r_{t+1}\right](3)}{\gamma\left[E_{t}\left(e r_{t+1}\right)^{2}\right](2)}
\end{aligned}
$$

The terms on the right hand side are related to saving, expected returns and risk. For each of them we now discuss their intuitive meaning and determinants.

\section{Portfolio Growth}

The first term on the right hand side of (35)-(36) represents portfolio growth, which measures outflows and inflows when Home and Foreign saving are invested abroad at the steady state portfolio share $1-z_{H}(0)$. The portfolio growth component depends entirely on Home and Foreign saving, which can be written as

$$
\begin{aligned}
s_{t}^{H}(1) & =\alpha_{s H} \Delta S_{t}(1)-0.5 z^{D}(0) \Delta q_{t}^{D}(1) \\
s_{t}^{F}(1) & =\alpha_{s F} \Delta S_{t}(1)+0.5 z^{D}(0) \Delta q_{t}^{D}(1)
\end{aligned}
$$

where $\alpha_{s H}$ and $\alpha_{s F}$ are zero-order vectors. Home and Foreign saving depend both on changes in publicly observed state variables and changes in relative asset prices. The latter generate wealth effects that impact consumption of the old generations. When the relative price of Home equity rises, the old generation in the Home country will be relatively wealthy and will consume this additional wealth. This lowers Home saving.

\section{Time-Varying Risk}

The other three terms driving capital inflows and outflows (35)-(36) are a result of portfolio reallocation due to changes in risk and expected returns. The second term represents capital flows due to changes in the variance of the excess return. An increase in the variance of the excess return makes portfolio diversification more attractive and therefore leads to an increase in both capital inflows and outflows. As can be seen from (34), the variance of the excess return only depends 
on publicly observed state variables. Time variation in the variance of the Home return relative to that of the Foreign return does not affect capital flows. From (31), we see that these moments only affect average portfolio shares. When there is an average shift towards Home equity, the market will equilibrate through a third-order rise in the relative Home equity price. This leads to a third-order drop in the expected excess return on Home equity, causing a first-order portfolio shift back towards Foreign equity. ${ }^{16}$ In the end capital flows remain unaffected.

\section{Average Expected Excess Return}

The third term on the right hand side of (35)-(36) represents capital flows due to the average change in the expected excess return. As discussed in detail in Tille and van Wincoop (2008), not all changes in expected excess returns generate capital flows. We have already discussed the example above where changes in expected returns equilibrate asset markets when there are time-varying second moments. No capital flows result from this. Another example is the adjustment following a rise in the relative price of Home equity. This raises the relative supply of Home equity and a third-order increase in the expected excess return on Home equity is necessary for investors to be willing to accept this shift in the composition of their portfolio. But no capital flows take place as a rise in the relative Home asset price automatically changes the portfolio composition without any asset trade.

The Technical Appendix derives all of the components determining changes in the equilibrium expected excess return. The only one that affects capital flows is denoted with an $I S$ superscript in (35) and (36). It is related to changes in saving and investment and is equal to

$$
\Delta \bar{E}_{t}^{A} e r_{t+1}(3)^{I S}=\frac{\gamma\left[E_{t}\left(e r_{t+1}\right)^{2}\right](2)}{4}\left[i_{t}^{D}(1)-z^{D}(0) s_{t}^{D}(1)\right]
$$

When relative investment is high in the Home country, it raises the relative supply of Home equity. A higher expected excess return on Home equity is then needed to clear asset markets. This leads to increased capital inflows and lower capital outflows. When relative saving in Home is high, there will be an excess demand for Home equity due to portfolio home bias. A lower expected excess return is then needed to clear asset markets, which leads to larger outflows and smaller inflows.

\footnotetext{
${ }^{16}$ As can be seen from (31) and (32), third-order changes in expected returns lead to first-order portfolio shifts as they are divided by a second-order variance of the excess return.
} 
Cross-country differences in saving and investment are equal to

$$
\begin{aligned}
s_{t}^{D}(1) & =\Delta a_{t}^{D}(1)+(1-\omega) \Delta k_{t}^{D}(1)-z^{D}(0) \Delta q_{t}^{D}(1) \\
i_{t}^{D}(1) & =\frac{1}{\xi} q_{t}^{D}(1)
\end{aligned}
$$

Relative asset prices affect relative saving through a wealth effect and relative investment through a standard Tobin's Q equation.

\section{Differences in Expected Returns across Countries}

The last term driving capital outflows and inflows in (35) and (36) represents changes in the average expected excess return of Home investors relative to Foreign investors. When investors from both countries become more optimistic about the expected excess return on their domestic equity, both capital outflows and inflows will drop. As can be seen from (33), this will happen when there is a positive future world productivity innovation $\varepsilon_{t+1}^{A}$ and investors have better quality information about domestic productivity innovations. Investors from both countries then believe that their own relative productivity will rise as they have better information on that, leading to a retrenchment towards domestic assets.

\section{Impact of Information Dispersion on Capital Flows}

In analyzing the impact of information dispersion on capital flows we will distinguish between gross capital flows, defined as outflows plus inflows, and net capital flows, defined as outflows minus inflows. The latter is also equal to the current account. ${ }^{17}$ In the absence of information dispersion capital flows (35)-(36) are entirely determined by the publicly observed state variables $S_{t}(1)$. Even unobserved portfolio shifts associated with $\tau_{t}^{D}$ do not have a first-order effect on capital flows in that case. A first-order portfolio shift from Foreign to Home leads to a third-order increase in the Home relative equity price. This leads to a third-order drop in the expected excess return on Home equity, which generates an entirely offsetting first-order portfolio shift back from Home to Foreign.

With dispersed information both gross and net capital flows are also affected by state variables that are not publicly observed. Figure 2 illustrates the channels through which this happens. The arrows on the left hand side of Figure 2 illustrate

\footnotetext{
${ }^{17}$ It is easily seen from (35)-(36) that outflows $s_{t}(1)-$ inflows $_{t}(1)=0.5\left(s_{t}^{D}(1)-i_{t}^{D}(1)\right)$. Using the equality $s^{H}+s^{F}=i^{H}+i^{F}$, this is equal to $s_{t}^{H}(1)-i_{t}^{H}(1)$, which is the current account.
} 
the impact of the unobserved state variables $\tau_{t}^{D}$ and $\varepsilon_{t+1}^{D}$ on net capital flows. We have already seen that they have a first-order effect on the relative asset price $q_{t}^{D}$ in the presence of private information. This affects saving and investment through a wealth effect and a Tobin's Q effect, which in turn affects net capital flows both through changes in the equilibrium expected excess return and through portfolio growth. ${ }^{18}$

The right hand side of Figure 2 illustrates the impact of the unobserved state variable $\varepsilon_{t+1}^{A}$ on gross capital flows. A rise in $\varepsilon_{t+1}^{A}$ leads agents from both countries to become more optimistic about the relative return on the asset from their own country. The resulting retrenchment leads to a drop in both capital inflows and outflows and therefore gross flows.

We can summarize these results in the form of two implications that capture the impact of dispersed information on both gross and net capital flows:

Implication 1 Capital flows are partially disconnected from current publicly observed fundamentals.

Implication 2 Capital flows help forecast future fundamentals, even after controlling for current fundamentals.

\section{Discussion}

Implications 1 and 2 are broader than the specifics of our model. They do not really depend on assumptions we made about the production side of the economy or preferences. The OLG assumption is not key either. It is only a tractable device to generate stationarity of the equilibrium. The implications also do not depend on how we introduced the noise in the economy through the cost of investing abroad; we could simply have introduced exogenous noise traders. The key assumption that drives Implications 1 and 2 is dispersed information. The specifics of how we introduced dispersed information are not important. We could for example have assumed that agents have private information about fundamentals further than

\footnotetext{
${ }^{18}$ To some extent these effects depend on portfolio home bias, which affects the impact of relative asset price changes on Home and Foreign saving and the impact of relative saving on the average expected excess return. See (37), (38) and (39).
} 
one period into the future, as in Bacchetta and van Wincoop (2006, 2008), ${ }^{19}$ or that within each country there are informed and uninformed agents (e.g. Wang (1994)).

While generalizing the model should not qualitatively change the impact of dispersed information as summarized in Implications 1 and 2, additional channels through which these implications come about are certainly possible. One example is an extension where agents work both periods of their life and have private information about their future labor income. Expectations of future labor income affect saving decisions, which affects capital flows through portfolio growth and the average expected excess return. Implication 1 will hold as this is private information. Implication 2 will hold as well as it is information about future labor income. This example also illustrates that asset prices are not necessarily the only channel through which private information can affect net capital flows.

One may also ask whether there are other models, without information dispersion, that lead to Implications 1 and 2. We have already seen that unobserved exogenous portfolio shifts $\tau_{t}^{D}$ do not have a first-order effect on asset prices and capital flows in the absence of private information. It is possible though to generate a disconnect by allowing for asset price bubbles, which we have ruled out. But this would only impact net, not gross capital flows. Moreover, it would be inconsistent with the second implication of the model as bubbles have no information content.

A final possibility may be that there is publicly available news about future fundamentals that is not controlled for by the econometrician. In that case Implications 1 and 2 would appear to hold even when there is no information dispersion. Such an argument has long been around to explain the disconnect been exchange rates and publicly observed fundamentals. However, this argument has been put to rest by the contributions of Evans and Lyons (2002) and others that document a close connection between exchange rates and order flow. This connection would not exist if all information is public as order flow aggregates private information. Public news affects asset prices without any order flow at all. ${ }^{20}$

\footnotetext{
${ }^{19}$ Such an extension, as well as others, does not fundamentally change the solution method other than that a larger model with more state variables would call for a numerical rather than analytic solution. As shown in Bacchetta and van Wincoop $(2006,2008)$, when agents have private information about fundamentals more than one period into the future asset prices are effected by higher order expectations of future fundamentals, but this does not change the solution method.

${ }^{20}$ Public news can lead to order flow if agents disagree about the interpretation of the news. But that is another example of private information, in this case about the nature or parameters
} 


\section{Quantitative Assessment}

We now evaluate the quantitative relevance of the two implications of the model, taking two complementary approaches. We first calibrate the model to data for 6 industrialized countries. This gives a good quantitative sense of the two implications within the context of the model and of the sensitivity to key parameters (extent of information dispersion, extent of information asymmetry and the extent of noise). The precise results will of course be sensitive to a variety of simplifying assumptions we made to obtain analytic tractability and transparency of the results. We therefore compliment the calibration results with an additional quantitative assessment that does not rely on the specific functional forms of the model.

The second approach uses regression analysis and Granger causality tests for the same 6 industrialized countries to quantify the extent of disconnect between capital flows and publicly observed fundamentals and the ability of capital flows to predict future asset payoffs conditional on observed fundamentals. This model free approach is useful because we have argued that Implications 1 and 2 of dispersed information apply more generally than to the specific model used here. Therefore we do not limit ourselves to the observed state variables $S_{t}$ in the model, but instead consider a broader set of observed macro variables.

It is also useful to explain what we will not do when evaluating the empirical relevance of the model. First, we do not take the expressions (35)-(36) for capital outflows and inflows to the data. Such expressions can also be derived in the absence of information dispersion. ${ }^{21}$ Information dispersion is only relevant to the extent that it impacts the various components of capital flows in (35)-(36), which leads to the two implications that we will focus on. Second, we do not use data on order flow. While such data have convincingly shown that asset prices aggregate private information, data on capital flows are not available at a daily frequency that would make such an analysis fruitful.

\footnotetext{
of the model.

${ }^{21}$ In the absence of information dispersion the last terms in (35)-(36) are obviously zero as expectations are identical across Home and Foreign agents.
} 


\subsection{Calibration Results}

We calibrate the model to annual data over the period 1977-2006 for the United States, Japan, Canada, United Kingdom, Germany and France, with the data sources described in Appendix F. Starting with the parameters related to production, we set the labor share $\omega$ equal to 0.54 , which is the average ratio of employee compensation to GDP in our sample. We estimate the persistence $\rho$ in the stochastic process for productivity by computing the Solow residuals and estimating a panel regression of $a_{i t}$ on its own lag and country-specific constants. This yields an estimate of $\rho$ of 0.91. It also yields an estimate of the standard deviation $\sigma_{a}$ of productivity innovations, but all moments we report below will be independent of the scale $\sigma_{a}$ of innovations.

The last two parameters associated with the supply side of the economy are the adjustment cost parameter $\xi$ and the rate of depreciation $\delta$. We set $\xi$ equal to 2.7 in order to match the standard deviation of annual real investment growth relative to the standard deviation of annual real GDP growth. This ratio is 2.8 in the data when averaged across the 6 countries and the sample 1977-2006. We set the rate of depreciation $\delta$ equal to 0.1 , which is the standard assumption for annual data in the entire real business cycle literature (e.g. Backus, Kehoe and Kydland (1992)).

We choose the average cost $\tau$ of investment abroad in order to match the observed portfolio home bias in the data. The standard measure of portfolio home bias is

$$
1-\frac{\text { share of foreign equity in portfolio of domestic investors }}{\text { share of foreign equity in world port folio }}
$$

Fidora, Fratzscher and Thimann (2007) report this measure of home bias for a wide range of countries based on 2001-2003 data. This includes 5 of our industrialized countries (all but Canada). The average measure of home bias for those 5 countries is 0.73 . They also report a measure of home bias for debt securities, which is virtually identical. We therefore set the cost $\tau$ of investment abroad such that the zero-order component of portfolio home bias in the model is equal to $0.73 .{ }^{22}$ The level of $\tau$ depends on the rate of relative risk-aversion, which we set at 5. Holding

\footnotetext{
${ }^{22}$ In the steady state of our symmetric setup this measure of home bias is also equal to $z^{D}(0)$. We set $\tau$ in the expression (30) for $z^{D}(0)$ to match the 0.73 home bias in the data. It implies that both countries invest a fraction 0.865 in domestic equity.
} 
the home bias constant, a change in the rate of risk-aversion has little effect on the results reported below.

While the parameters outlined above are standard in the literature, we also need to set values for three parameters that are specific to our model. These are the average dispersion of private signals across investors, $\left(\sigma_{H H}+\sigma_{H F}\right) / 2$, the relative precision of signals on domestic and foreign innovations, $\sigma_{H F} / \sigma_{H H}$, and the volatility of noise shocks relative to productivity innovations, $\theta$.

We set the average dispersion of private signals, $\left(\sigma_{H H}+\sigma_{H F}\right) / 2$, to generate a cross-sectional dispersion of expected asset price changes that matches the evidence from surveys of forecasters. More specifically, we match the standard deviation of the cross-sectional distribution of $E_{t}^{H j} q_{t+1}^{H}$, scaled by the unconditional variance of $\Delta q_{t}^{H}$. The advantage of scaling the cross-sectional distribution this way is that the result in the model does not depend on the scale of model innovations measured by $\sigma_{a}$.

We measure the dispersion of expected asset price changes by using a survey from the International Center for Finance at the Yale School of Management that reports expected stock price changes by a large number of financial institutions. ${ }^{23}$ The survey has data for two countries, the United States and Japan. For both countries the survey asks about expected percentage change in the stock price (respectively Dow Jones Industrial Index and Nikkei Dow) over the next 1, 3, and 12 months, with our parametrization focusing on the 1-year ahead forecasts. For each country the survey is based on about 400 financial institutions. ${ }^{24}$ The survey starts in 1989 with six-month interval surveys until 1998, after which monthly surveys are conducted. ${ }^{25}$ We have collected the data through October 2004.

Since it is important to compare expectations at the same point in time, and financial institutions do not all respond to the survey on the same day, we only consider the cross sectional distribution of responses that take place on the same

\footnotetext{
${ }^{23}$ We would like to thank the International Center for Finance for making these data available to us.

${ }^{24}$ For Japan the survey is mailed to most of the major financial institutions, including 165 banks, 46 insurance companies, 113 security companies and 45 investment trust companies. For the U.S. about 400 randomly drawn institutions are selected from "Investment Managers "in the "Money Market Directory of Pension Funds and their Investment Managers".

${ }^{25}$ See Shiller et al. (1996) and http://icf.som.yale.edu/confidence.index/explanations.html for more details.
} 
day. ${ }^{26}$ The average cross-sectional standard deviation of the expected one-year percentage stock price change across respondents is 0.1278 for the U.S. and 0.1341 for Japan. This is scaled by the variance of stock price changes. Here we use historical numbers of the standard deviation of stock price changes from Jorion and Goetzmann (1999), which are respectively 0.1584 and 0.1579 for the U.S. and Japan. Our scaled measure of dispersion of expected stock price changes is then 4.99 for the U.S. and 5.23 for Japan. In the model we set $\left(\sigma_{H H}+\sigma_{H F}\right) / 2=0.22$, which leads to a scaled measure of dispersion of expected stock price changes of 5.03, close to that for both the U.S. and Japan.

As $\sigma_{H F} / \sigma_{H H}$ and $\theta$ are hard to calibrate, we vary them over a wide range. Under the benchmark we set $\theta=100$ and $\sigma_{H F} / \sigma_{H H}=1.5$. Holding $\left(\sigma_{H H}+\sigma_{H F}\right) / 2=$ 0.22 remains broadly consistent with the evidence on information dispersion even when we vary $\theta$ and $\sigma_{H F} / \sigma_{H H}$ over a wide range. ${ }^{27}$

The results are reported in 6 panels in Figure 3. The top 3 panels relate to Implication 1. They report the fraction of the variance of gross and net capital flows explained by unobserved state variables, as a function of respectively $\left(\sigma_{H H}+\right.$ $\left.\sigma_{H F}\right) / 2, \sigma_{H F} / \sigma_{H H}$ and $\theta$. The bottom three panels relate to Implication 2 , and report the $R^{2}$ of a regression of $\varepsilon_{t+1}^{D}$ on net capital flows at time $t$ and $\varepsilon_{t+1}^{A}$ on gross capital flows at time $t$.

For the benchmark parameterization the fraction of the variance of both gross and net capital flows explained by unobserved state variables is $49 \%{ }^{28}$ As expected, panel A shows that the disconnect gradually disappears when the standard deviation of the errors in the signals becomes large. In that case the private signals have little information content and the dispersion of information goes away. The scaled measure of cross-sectional dispersion of expectations of asset price changes (not reported) goes to zero as well.

Panel B shows the disconnect as a function of the extent of information asymmetry across countries. This is not relevant for net capital flows, but the disconnect for gross capital flows relies entirely on the information asymmetry. We see that

\footnotetext{
${ }^{26}$ Moreover, we eliminate days were there were fewer than 5 responses.

${ }^{27}$ The scaled measure of dispersion of expected stock price changes varies from 4.3 to 5.6 when varying $\sigma_{H F} / \sigma_{H H}$ from 1.01 to 2 . The range is 3.8 to 6.4 when we vary $\theta$ from 1 to 1000 .

${ }^{28}$ The disconnect would be even larger if we had introduced private information about fundamentals further into the future and persistence of the noise in the model. Both features are present in Bacchetta and van Wincoop (2006) in the context of a NRE model for exchange rate determination.
} 
introducing only a very small degree of information asymmetry is sufficient to get close to the full impact on disconnect. It makes little difference for the disconnect whether $\sigma_{H F}$ is $5 \%$ or $100 \%$ higher than $\sigma_{H H} \cdot{ }^{29}$

Panel $\mathrm{C}$ shows that the disconnect is virtually independent of the variance of the noise, which is proportional to $\theta$. We report results for $\theta$ ranging from 1 to 1000. A higher $\theta$ reduces the contribution of $\varepsilon_{t+1}^{D}$ to the variance of net capital flows while raising the contribution of the noise $\tau_{t}^{D}$, leaving the overall contribution of these unobserved state variables almost unchanged. The reduced contribution of $\varepsilon_{t+1}^{D}$ is a result of the reduced information content of the relative asset price due to the increased noise. Therefore less is known about $\varepsilon_{t+1}^{D}$.

Turning to Implication 2 of the model, panel D shows that the information content of both net and gross capital flows is negatively related to the standard deviaton of the errors of the private signals. It goes to zero when the private signals become very weak (panel D). More interesting though is the difference in the information content when comparing gross and net capital flows. The last two panels show that the explanatory power of gross capital flows at $t$ for $\varepsilon_{t+1}^{A}$ is quite robust. Panel E shows that only a small degree of information asymmetry is required, while panel $\mathrm{F}$ shows that it is not sensitive to $\theta$.

By contrast, the explanatory power of net capital flows at $t$ for $\varepsilon_{t+1}^{D}$ is much more limited and less robust. This is due to the noise, which only affects net capital flows and reduces its information content. Panel F shows that introducing more noise through a higher $\theta$ quickly evaporates the information content of net capital flows. The $R^{2}$ of a regression of $\epsilon_{t+1}^{D}$ on net capital flows declines rapidly with $\theta$. This is a result both of the increased importance of the noise and the reduced weight of $\epsilon_{t+1}^{D}$ due to the lower information content of the relative asset price.

\footnotetext{
${ }^{29}$ Even under the benchmark parameterization, where $\sigma_{H F} / \sigma_{H H}=1.5$, the average absolute forecast error of Home productivity innovations is only $0.14 \%$ higher for Foreign investors than for Home investors (based on the estimated $\sigma_{a}=0.0127$ ). To provide some perspective, Bae, Stulz and Tan (2007) report that the absolute forecast error of annual earnings per share is $7.8 \%$ higher for foreign analysts than local analysts. This is not fully comparable to our model though as it refers to earnings forecasts of individual firms rather than the entire economy. Nonetheless it shows that the extent of information asymmetry in the model is not excessive by any means.
} 


\subsection{Evidence from Six Industrialized Countries}

\subsubsection{Disconnect from Publicly Observed Fundamentals}

We now turn to a model free approach to evaluating Implications 1 and 2. For the first implication of the model, we estimate a VAR to evaluate the explanatory power of innovations in macro variables for capital flow fluctuations over various horizons. We use quarterly data from 1977(1) to 2007(2), and report results for both gross and net capital flows. Gross capital flows are again defined as outflows plus inflows and net capital flows as outflows minus inflows. We measure the latter as the current account in most of the results reported, but findings are similar when measured using financial flows. Capital flows are expressed as a share of GDP.

For gross capital flows we estimate a VAR that includes the following variables: world GDP growth, world inflation, world interest rate (T-bill rate), world budget deficit (share of GDP) and gross capital flows. All world variables are computed as a GDP-weighted average of the variables across all countries. For net capital flows we estimate a VAR that includes: relative GDP growth, relative inflation, relative T-bill rate, relative budget deficit (share of GDP) and net capital flows. Relative refers to the difference between the variable in the country minus a GDP-weighted average of that in the other countries. Identification of the innovations is achieved using the Choleski decomposition with the ordering of the variables as listed above. Three lags of all variables are included in the VAR.

The results are reported in Table 1 . The macro variables have very limited explanatory power for gross capital flows. At a one-quarter horizon only $6 \%$ of the variance of gross capital flows can be accounted for by innovations in the macro variables. Even at a 12-quarter horizon only $16 \%$ of the variance of gross capital flows is explained by innovations in the macro variables. Results are only slightly better for the current account, where respectively $7 \%$ and $32 \%$ of the variance of the current account at 1 and 12-quarter horizons can be explained by innovations in publicly observed macro variables.

These results are consistent with the first implication of the model. It is possible though that the limited explanatory power of publicly observed macro variables is due to measurement error in both gross and net capital flow data. Such measurement error is likely to be much more severe for quarterly data than for annual data. In the remainder of this section we therefore focus the analysis on annual data. In Table 2 we repeat the previous exercise using 30 annual observations 
from 1977 to 2006, including only one lag in the VAR. Consistent with the view that capital flows are better measured for annual than for quarterly data, we now find that a larger fraction of capital flow fluctuations can be accounted for by the macro variables. For gross capital flows we find that respectively $21 \%$ and $30 \%$ of the variance is explained by innovations in the macro variables at 1 and 3-year horizons. For the current account these numbers are $34 \%$ and $53 \%$.

But this still leaves most gross and net capital flow fluctuations unexplained. Moreover, this significantly overstates the true explanatory power of publicly observed macroeconomic variables because of the relatively small sample of 30 annual observations. It needs to be compared to what we would get when the macro variables are generated by pure noise. In order to make this comparison, for each country we generate an artificial series of macro variables from an $\mathrm{AR}(1)$ process with the same persistence as the actual macro variables for that country and randomly generated $N(0,1)$ innovations. We then compute the average variance de-

composition based on 1000 estimations of the VARs with the randomly generated macro variables.

We find that the fraction of the variance of gross flows explained at 1 and 3 -year horizons by the random innovations in the macro variables is on average respectively $17 \%$ and $27 \%$. For the current account these numbers are $18 \%$ and $29 \%$. This implies that for gross capital flows the actual macro variables have virtually no explanatory power at all as the results in Table 2 are very close to what we would get if the macro variables were generated by pure noise. For net capital flows we find very limited true explanatory power as the fraction of the variance of net capital flows that can be explained by the actual macro variables is only 16 to 24 percentage points higher than that generated by random noise.

\subsubsection{Information Content of Capital Flows}

We next turn to the second implication of the model. The calibration results indicate that the information content of gross capital flows is stronger and more robust than for net capital flows. It should therefore be easier to detect the information content of gross capital flows than net capital flows. Noise in the model does not affect gross capital flows. It only affects net capital flows and the relative asset price, which reduces their information content. This in turn reduces the knowledge that agents have about $\varepsilon_{t+1}^{D}$, which reduces its weight in the equilibrium relative 
asset price and net capital flows, which further reduces their information content.

This point is also illustrated in Bacchetta and van Wincoop (2006) in the context of a NRE model of exchange rate determination. In their benchmark calibration the presence of dispersed information leads to a significant disconnect between exchange rates and publicly observed fundamentals. It reduces the explanatory power of observed fundamentals for one-period exchange rate changes from close to $100 \%$ to $14 \%$. But they find that the equilibrium exchange rate contains only very limited information about future fundamentals. It is therefore not surprising that evidence on the information content of exchange rates is not overwhelming. Based on 36 bivariate Granger causality tests (6 countries and 6 different macro variables), Engel and West (2005) find statistically significant causality from exchange rate changes to future macro variables in only one third, or 12 , of the cases.

We conduct separate Granger causality tests for gross and net capital flows. The theory implies that gross capital flows negatively predict future world productivity $\varepsilon_{t+1}^{A}$ and net capital outflows (or the current account) negatively predict relative future productivity $\varepsilon_{t+1}^{D}$. The model makes no distinction between future productivity innovations, future GDP innovations and future innovations in asset payoffs. They are all driven by the same productivity shocks. However, it is private information about future asset payoffs that is ultimately responsible for the information content of asset prices and capital flows in the model. We therefore ask to what extent capital flows Granger cause the aggregate profit rate. The latter is defined as GDP minus employee compensation, divided by the capital stock.

\section{Information Content Gross Capital Flows}

The implication of the model that gross capital flows contain information about

$\varepsilon_{t+1}^{A}$ is then be tested by evaluating to what extent gross capital flows Granger cause the "world profit rate". The latter is defined as a GDP-weighted average of profit rates of all countries. We report results only for annual data as they suffer less from measurement error than quarterly data.

The results are reported in Table 3. The second column reports results from a bivariate Granger causality test. We regress the world profit rate on one lag of itself and one lag of gross capital flows. We test the null hypothesis that lagged gross capital flows fail to cause the world profit rate. Rejection of the null hypothesis implies Granger causality. The table reports p-values for countries where we 
reject the null-hypothesis at a significance level of $10 \%$ or better. In four of the six countries we find strong evidence of Granger causality. Moreover, while not reported in the table, in each of these four cases the direction of the causality is as predicted by the theory. The coefficient on the lagged gross capital flows is always negative.

The third and fourth columns of Table 3 confirm that these findings are robust to the inclusion of lagged values of other macro variables. We regress the world profit rate on its own lag and lagged values of gross capital flows and GDPweighted averages of a set of additional macro variables. We again test whether the coefficient on lagged gross capital flows is significantly different from zero. This is the case for five of the six countries when including GDP-weighted averages of lags of real GDP growth, inflation and the T-bill rate and for four out of the six countries when additionally including a GDP-weighted average of budget deficits as a share of GDP. Moreover, in all of these cases we find that the coefficient on lagged gross capital flows is negative as predicted by the theory. ${ }^{30}$

\section{Information Content Net Capital Flows}

There is less evidence in favor of the hypothesis that net capital flows Granger cause the relative profit rate, defined as the profit rate minus the GDP-weighted average profit rate of the other countries. The results are reported in Table 4. We first again conduct a bivariate Granger causality test. We regress the relative profit rate on its own lag and the lagged value of net capital outflows. We find that the coefficient on the lagged profit rate is significantly different from zero in two of the six countries. This is the case both when measuring net capital outflows as outflows minus inflows and as the current account. We find even less significance when introducing lags of other macro variables. In addition, in cases where we do find significance the sign is positive. This is in contrast to the model, which implies that net outflows negatively predict the relative profit rate.

These findings are not necessarily inconsistent with the model though. To the contrary, they can be viewed as further confirmation of the theory. The calibration exercise anticipated these results by showing that the information content of gross capital flows is stronger and more robust than that for net capital flows. The noise

\footnotetext{
${ }^{30}$ While not reported, these results continue to hold up when we include a linear time trend in the regressions. The justification for doing so is that gross capital flows have increased over our sample for reasons that are unrelated to our model.
} 
in the model, and its interaction with private information, is responsible for the weak information content of net capital flows.

\section{Conclusion}

We have developed a new theory of international capital flows based on dispersed information. The theory is innovative in that it integrates dispersed information into a DSGE open economy macro model with portfolio choice to develop implications for gross and net capital flows. It leads to a fundamentally different view of what drives both gross and net capital flows than standard models based on common information. We have emphasized two important implications, which are specific to models with dispersed information. First, capital flows become partially disconnected from current publicly observed fundamentals. Second, capital flows help forecast future fundamentals, even after controlling for current fundamentals.

A calibration exercise has shown that the disconnect between capital flows and macro variables is not very sensitive to the extent of noise in the model and information asymmetry across countries. By contrast, the information content of net capital flows can be significantly reduced by noise while the information content of gross capital flows is quite robust. These implications of the theory are confirmed for six industrialized countries. Publicly observed macro variables have very limited explanatory power for both gross and net capital flows. Gross capital flows contain information about future fundamentals in the way predicted by the theory, while net capital flows do not exhibit strong information content. 


\section{Appendix}

\section{A Equations of the model}

The various equations of the model are written in terms of the logs of the variables, denoted by lower-case letters. We denote the worldwide average of log equity prices by $q_{t}^{A}=0.5\left(q_{H, t}+q_{F, t}\right)$, and the cross-country difference in log equity prices by $q_{t}^{D}=q_{H, t}-q_{F, t}$. We define similar variables for the capital stock $\left(k_{t+1}^{A}, k_{t+1}^{D}\right)$, productivity $\left(a_{t}^{A}, a_{t}^{D}\right)$ and asset returns $\left(r_{t+1}^{A}, r_{t+1}^{D}=e r_{t+1}\right)$.

Using the capital dynamics (2), the Tobin's Q equation (5) in Home and Foreign becomes:

$$
\begin{aligned}
e^{k_{t+1}^{A}+\frac{1}{2} k_{t+1}^{D}} & =\left(1+\frac{e^{q_{t}^{A}+\frac{1}{2} q_{t}^{D}}-1}{\xi}\right) e^{k_{t}^{A}+\frac{1}{2} k_{t}^{D}} \\
e^{k_{t+1}^{A}-\frac{1}{2} k_{t+1}^{D}} & =\left(1+\frac{e^{q_{t}^{A}-\frac{1}{2} q_{t}^{D}}-1}{\xi}\right) e^{k_{t}^{A}-\frac{1}{2} k_{t}^{D}}
\end{aligned}
$$

Using the wage (3), the consumption Euler equations (14) and (17) are:

$$
\begin{aligned}
& \left(\omega e^{\left.a_{t}^{A}+\frac{1}{2} a_{t}^{D}+(1-\omega)\left(k_{t}^{A}+\frac{1}{2} k_{t}^{D}\right)-c_{y t}^{H j}-1\right)^{\gamma}}=\beta E_{t}^{H j} e^{(1-\gamma) r_{t+1}^{p, H j}}\right. \\
& \left(\omega e^{\left.a_{t}^{A}-\frac{1}{2} a_{t}^{D}+(1-\omega)\left(k_{t}^{A}-\frac{1}{2} k_{t}^{D}\right)-c_{y t}^{F j}-1\right)^{\gamma}}=\beta E_{t}^{F j} e^{(1-\gamma) r_{t+1}^{p, F j}}\right.
\end{aligned}
$$

The portfolio Euler equations for individual investors (15) and (18) are:

$$
\begin{aligned}
& 0=E_{t}^{H j}\left(e^{-\gamma r_{t+1}^{p, H j}+r_{t+1}^{A}+\frac{1}{2} e r_{t+1}}-e^{-\gamma r_{t+1}^{p, H j}-\tau_{H j, t}+r_{t+1}^{A}-\frac{1}{2} e r_{t+1}}\right) \\
& 0=E_{t}^{F j}\left(e^{-\gamma r_{t+1}^{p, F j}-\tau_{F j, t}+r_{t+1}^{A}+\frac{1}{2} e r_{t+1}}-e^{-\gamma r_{t+1}^{p, F j}+r_{t+1}^{A}-\frac{1}{2} e r_{t+1}}\right)
\end{aligned}
$$

The asset market clearing conditions (19)-(20) are:

$$
\begin{aligned}
e^{k_{t+1}^{A}+\frac{1}{2} k_{t+1}^{D}+q_{t}^{A}+\frac{1}{2} q_{t}^{D}}= & \int\left(\omega e^{a_{t}^{A}+\frac{1}{2} a_{t}^{D}+(1-\omega)\left(k_{t}^{A}+\frac{1}{2} k_{t}^{D}\right)}-e^{c_{y t}^{H j}}\right) z_{H j, t} d j \\
& +\int\left(\omega e^{a_{t}^{A}-\frac{1}{2} a_{t}^{D}+(1-\omega)\left(k_{t}^{A}-\frac{1}{2} k_{t}^{D}\right)}-e^{c_{y t}^{F j}}\right) z_{F j, t} d j \\
e^{k_{t+1}^{A}-\frac{1}{2} k_{t+1}^{D}+q_{t}^{A}-\frac{1}{2} q_{t}^{D}}= & \int\left(\omega e^{a_{t}^{A}+\frac{1}{2} a_{t}^{D}+(1-\omega)\left(k_{t}^{A}+\frac{1}{2} k_{t}^{D}\right)}-e^{c_{y t}^{H j}}\right)\left(1-z_{H j, t}\right) d j \\
& +\int\left(\omega e^{a_{t}^{A}-\frac{1}{2} a_{t}^{D}+(1-\omega)\left(k_{t}^{A}-\frac{1}{2} k_{t}^{D}\right)}-e^{c_{y t}^{F j}}\right)\left(1-z_{F j, t}\right) d j
\end{aligned}
$$


The rates of return on Home and Foreign equity (6)-(7) are given by:

$$
\begin{aligned}
e^{r_{t+1}^{A}+\frac{1}{2} e r_{t+1}}= & (1-\omega) e^{a_{t+1}^{A}+\frac{1}{2} a_{t+1}^{D}-\omega\left(k_{t+1}^{A}+\frac{1}{2} k_{t+1}^{D}\right)-q_{t}^{A}-\frac{1}{2} q_{t}^{D}} \\
& +(1-\delta) e^{q_{t+1}^{A}+\frac{1}{2} q_{t+1}^{D}-q_{t}^{A}-\frac{1}{2} q_{t}^{D}} \\
e^{r_{t+1}^{A}-\frac{1}{2} e r_{t+1}}= & (1-\omega) e^{a_{t+1}^{A}-\frac{1}{2} a_{t+1}^{D}-\omega\left(k_{t+1}^{A}-\frac{1}{2} k_{t+1}^{D}\right)-q_{t}^{A}+\frac{1}{2} q_{t}^{D}} \\
& +(1-\delta) e^{q_{t+1}^{A}-\frac{1}{2} q_{t+1}^{D}-q_{t}^{A}+\frac{1}{2} q_{t}^{D}}
\end{aligned}
$$

The portfolio returns of individual investors (13) and (16) are:

$$
\begin{aligned}
e^{r_{t+1}^{p, H j}} & =z_{H j, t} e^{r_{t+1}^{A}+\frac{1}{2} e r_{t+1}}+\left(1-z_{H j, t}\right) e^{r_{t+1}^{A}-\frac{1}{2} e r_{t+1}-\tau_{H j, t}} \\
e^{r_{t+1}^{p, F j}} & =z_{F j, t} e^{r_{t+1}^{A}+\frac{1}{2} e r_{t+1}-\tau_{F j, t}}+\left(1-z_{F j, t}\right) e^{r_{t+1}^{A}-\frac{1}{2} e r_{t+1}}
\end{aligned}
$$

In terms of the zero order allocation, we normalize productivity to unity in both countries, so $a(0)=0$. The relative price of capital is unity, implying $q(0)=0$. The zero order components of the rate of return, capital and consumption of young agents are:

$$
\begin{aligned}
e^{r(0)} & =(1-\omega) e^{-\omega k(0)}+(1-\delta) \\
e^{c_{y}(0)} & =\omega e^{(1-\omega) k(0)}-e^{k(0)}
\end{aligned}
$$

where the capital $k(0)$ solves:

$$
\left(\omega e^{-\omega k(0)}-1\right)^{-\gamma}=\beta\left[(1-\omega) e^{-\omega k(0)}+(1-\delta)\right]^{1-\gamma}
$$

The ratio of young consumption to the wage is:

$$
\bar{c}=\frac{1}{\omega} e^{c_{y}(0)-(1-\omega) k(0)}=1-\frac{e^{\omega k(0)}}{\omega}
$$

The average portfolio share is computed from the asset market clearing (48):

$$
z^{A}(0)=\frac{z_{H}(0)+z_{F}(0)}{2}=\frac{1}{2}
$$

\section{B Signal extraction}

\section{General approach}

We focus on the signal extraction of Home investors. The inference for Foreign investors is computed along similar lines. 
A Home investor infers the Home and Foreign future productivity shocks, $\varepsilon_{t+1}^{H}$ and $\varepsilon_{t+1}^{F}$ from three types of signals. The first is the relative asset price, $q_{t}^{D}$, which together with the publicly observed state variables (22) reveals $x_{t}^{D}$ from (21). The second is the set of private signals on Home and Foreign future productivity shocks, $v_{j, t}^{H, H}$ and $v_{j, t}^{H, F}$ from (8)-(11). The third is the unconditional distribution of $\varepsilon_{t+1}^{H}$ and $\varepsilon_{t+1}^{F}$.

The signal extraction problem therefore consists of inferring a vector $\xi_{t+1}=$ $\left|\varepsilon_{H, t+1}, \varepsilon_{F, t+1}\right|^{\prime}$ conditional on a vector of signals $Y_{t}^{H j}=\left|x_{t}^{D}, v_{j, t}^{H, H}, v_{j, t}^{H, F}, 0,0\right|^{\prime}$ which are linked as follows:

$$
Y_{t}^{H j}=X^{H} \xi_{t+1}+v_{t}^{H j}
$$

where $X^{H}$ is a 5 by 2 matrix and $v_{t}^{H j}$ is a vector of independent innovations with a diagonal variance matrix $R^{H}$ :

$$
X^{H}=\left|\begin{array}{cc}
1 & -1 \\
1 & 0 \\
0 & 1 \\
1 & 0 \\
0 & 1
\end{array}\right| \quad ; \quad \operatorname{diag}\left(R^{H}\right)=\left|\begin{array}{c}
4 \lambda^{2} \theta \sigma_{a}^{2} \\
\sigma_{H H}^{2} \\
\sigma_{H F}^{2} \\
\sigma_{a}^{2} \\
\sigma_{a}^{2}
\end{array}\right|
$$

The projection theorem implies that $\xi_{t+1}$ is then normally distributed with mean $\hat{\xi}_{t+1}$ and variance $V\left(\hat{\xi}_{t+1}\right)$ corresponding to GLS estimation:

$\hat{\xi}_{t+1}=\left[\left(X^{H}\right)^{\prime}\left(R^{H}\right)^{-1} X^{H}\right]^{-1}\left(X^{H}\right)^{\prime}\left(R^{H}\right)^{-1} Y_{t}^{H j} \quad ; \quad V\left(\hat{\xi}_{t+1}\right)=\left[\left(X^{H}\right)^{\prime}\left(R^{H}\right)^{-1} X^{H}\right]^{-1}$

\section{Expected productivity shocks}

Writing out the matrices above, the expected values of future Home and Foreign productivities become:

$$
\begin{aligned}
& E_{t}^{H j}\left(\varepsilon_{H, t+1}\right)=\alpha_{\varepsilon H, x D}^{H j} x_{t}^{D}+\alpha_{\varepsilon H, v H}^{H j} v_{j, t}^{H, H}+\alpha_{\varepsilon H, v F}^{H j} v_{j, t}^{H, F} \\
& E_{t}^{H j}\left(\varepsilon_{F, t+1}\right)=\alpha_{\varepsilon F, x D}^{H j} x_{t}^{D}+\alpha_{\varepsilon F, v H}^{H j} v_{j, t}^{H, H}+\alpha_{\varepsilon F, v F}^{H j} v_{j, t}^{H, F}
\end{aligned}
$$


where:

$$
\begin{aligned}
\alpha_{\varepsilon H, x D}^{H j} & =\frac{1}{V}\left(\frac{\sigma_{a}^{2}}{\sigma_{H, F}^{2}}+1\right) \frac{1}{2 \lambda^{2} \theta} \\
\alpha_{\varepsilon H, v H}^{H j} & =\frac{1}{V}\left[\frac{1}{2 \lambda^{2} \theta}+\left(\frac{\sigma_{a}^{2}}{\sigma_{H, F}^{2}}+1\right) 2\right] \frac{\sigma_{a}^{2}}{\sigma_{H, H}^{2}} \\
\alpha_{\varepsilon H, v F}^{H j} & =\frac{1}{V} \frac{1}{2 \lambda^{2} \theta} \frac{\sigma_{a}^{2}}{\sigma_{H, F}^{2}} \\
\alpha_{\varepsilon F, x D}^{H j} & =-\frac{1}{V}\left(\frac{\sigma_{a}^{2}}{\sigma_{H, H}^{2}}+1\right) \frac{1}{2 \lambda^{2} \theta} \\
\alpha_{\varepsilon F, v H}^{H j} & =\frac{1}{V} \frac{1}{2 \lambda^{2} \theta} \frac{\sigma_{a}^{2}}{\sigma_{H, H}^{2}} \\
\alpha_{\varepsilon F, v F}^{H j} & =\frac{1}{V}\left[\frac{1}{2 \lambda^{2} \theta}+\left(\frac{\sigma_{a}^{2}}{\sigma_{H, H}^{2}}+1\right) 2\right] \frac{\sigma_{a}^{2}}{\sigma_{H, F}^{2}}
\end{aligned}
$$

and:

$$
V=\left(\frac{\sigma_{a}^{2}}{\sigma_{H, H}^{2}}+1\right)\left(\frac{\sigma_{a}^{2}}{\sigma_{H, F}^{2}}+1\right) 2+\frac{1}{2 \lambda^{2} \theta}\left(\frac{\sigma_{a}^{2}}{\sigma_{H, F}^{2}}+\frac{\sigma_{a}^{2}}{\sigma_{H, H}^{2}}+2\right)
$$

While these coefficients are complex functions, we can distinguish between their various orders. We consider components up to order two. The coefficients on $x_{t}^{D}$ $\left(\alpha_{\varepsilon H, x D}^{H j}\right.$ and $\left.\alpha_{\varepsilon F, x D}^{H j}\right)$ only have components of order zero and two:

$$
\begin{aligned}
& {\left[\alpha_{\varepsilon H, x D}^{H j}\right](0)=-\left[\alpha_{\varepsilon F, x D}^{H j}\right](0)=\frac{1}{2\left(1+2 \lambda^{2} \theta\right)}} \\
& {\left[\alpha_{\varepsilon H, x D}^{H j}\right](2)=-\sigma_{a}^{2} \frac{\sigma_{H, F}^{2}-\sigma_{H, H}^{2}+4 \lambda^{2} \theta \sigma_{H, F}^{2}}{4\left(1+2 \lambda^{2} \theta\right)^{2} \sigma_{H, H}^{2} \sigma_{H, F}^{2}}} \\
& {\left[\alpha_{\varepsilon F, x D}^{H j}\right](2)=\sigma_{a}^{2} \frac{-\sigma_{H, F}^{2}+\sigma_{H, H}^{2}+4 \lambda^{2} \theta \sigma_{H, H}^{2}}{4\left(1+2 \lambda^{2} \theta\right)^{2} \sigma_{H, H}^{2} \sigma_{H, F}^{2}}}
\end{aligned}
$$

The coefficients on the private signals only have components of order two:

$$
\begin{aligned}
& {\left[\alpha_{\varepsilon H, v H}^{H j}\right](2)=\frac{1+4 \lambda^{2} \theta}{2\left(1+2 \lambda^{2} \theta\right)} \frac{\sigma_{a}^{2}}{\sigma_{H, H}^{2}} \quad, \quad\left[\alpha_{\varepsilon H, v F}^{H j}\right](2)=\frac{1}{2\left(1+2 \lambda^{2} \theta\right)} \frac{\sigma_{a}^{2}}{\sigma_{H, F}^{2}}} \\
& {\left[\alpha_{\varepsilon F, v H}^{H j}\right](2)=\frac{1}{2\left(1+2 \lambda^{2} \theta\right)} \frac{\sigma_{a}^{2}}{\sigma_{H, H}^{2}} \quad, \quad\left[\alpha_{\varepsilon F, v F}^{H j}\right](2)=\frac{1+4 \lambda^{2} \theta}{2\left(1+2 \lambda^{2} \theta\right)} \frac{\sigma_{a}^{2}}{\sigma_{H, F}^{2}}}
\end{aligned}
$$


The various orders of the Home agent's expectations of future Home productivity are then:

$$
\begin{aligned}
& {\left[E_{t}^{H j}\left(\varepsilon_{H, t+1}\right)\right](1)=-\left[E_{t}^{H j}\left(\varepsilon_{F, t+1}\right)\right](1)=\frac{1}{2\left(1+2 \lambda^{2} \theta\right)} x_{t}^{D}} \\
& {\left[E_{t}^{H j}\left(\varepsilon_{H, t+1}\right)\right](2)=\frac{\sigma_{a}^{2}}{2\left(1+2 \lambda^{2} \theta\right)}\left[\frac{1+4 \lambda^{2} \theta}{\sigma_{H, H}^{2}} \epsilon_{j, t}^{H, H}+\frac{1}{\sigma_{H, F}^{2}} \epsilon_{j, t}^{H, F}\right]} \\
& {\left[E_{t}^{H j}\left(\varepsilon_{F, t+1}\right)\right](2)=\frac{\sigma_{a}^{2}}{2\left(1+2 \lambda^{2} \theta\right)}\left[\frac{1}{\sigma_{H, H}^{2}} \epsilon_{j, t}^{H, H}+\frac{1+4 \lambda^{2} \theta}{\sigma_{H, F}^{2}} \epsilon_{j, t}^{H, F}\right]}
\end{aligned}
$$

A useful result is the third-order component of the expected productivity difference:

$$
\begin{aligned}
& {\left[E_{t}^{H j}\left(\varepsilon_{H, t+1}-\varepsilon_{F, t+1}\right)\right](3) } \\
= & \frac{-\lambda^{2} \theta \sigma_{a}^{2}}{\left(1+2 \lambda^{2} \theta\right)^{2}} \frac{\sigma_{H, H}^{2}+\sigma_{H, F}^{2}}{\sigma_{H, H}^{2} \sigma_{H, F}^{2}} x_{t}^{D}+\frac{2 \lambda^{2} \theta \sigma_{a}^{2}}{1+2 \lambda^{2} \theta}\left(\frac{\varepsilon_{H, t+1}}{\sigma_{H, H}^{2}}-\frac{\varepsilon_{F, t+1}}{\sigma_{H, F}^{2}}\right)
\end{aligned}
$$

\section{Variance of productivity shocks}

The Home agent also infers the variances and covariances of the productivities shocks:

$$
\begin{aligned}
\operatorname{Var}_{t}^{H j}\left(\varepsilon_{H, t+1}\right) & =\frac{\sigma_{a}^{2}}{V}\left[\frac{1}{2 \lambda^{2} \theta}+\left(\frac{\sigma_{a}^{2}}{\sigma_{H, F}^{2}}+1\right) 2\right] \\
\operatorname{Var}_{t}^{H j}\left(\varepsilon_{F, t+1}\right) & =\frac{\sigma_{a}^{2}}{V}\left[\frac{1}{2 \lambda^{2} \theta}+\left(\frac{\sigma_{a}^{2}}{\sigma_{H, H}^{2}}+1\right) 2\right] \\
\operatorname{Cov}_{t}^{H j}\left(\varepsilon_{H, t+1}, \varepsilon_{F, t+1}\right) & =\frac{\sigma_{a}^{2}}{V} \frac{1}{2 \lambda^{2} \theta}
\end{aligned}
$$

These terms only have second-order components (zero, first and third-order components zero):

$$
\begin{aligned}
\operatorname{Var}_{t}^{H j}\left(\varepsilon_{H, t+1}\right)(2) & =\operatorname{Var}_{t}^{H j}\left(\varepsilon_{F, t+1}\right)(2)=\frac{\left(1+4 \lambda^{2} \theta\right) \sigma_{a}^{2}}{2\left(1+2 \lambda^{2} \theta\right)} \\
\operatorname{Cov}_{t}^{H j}\left(\varepsilon \varepsilon_{H, t+1}, \varepsilon_{F, t+1}\right)(2) & =\frac{\sigma_{a}^{2}}{2\left(1+2 \lambda^{2} \theta\right)}
\end{aligned}
$$


The expected values of squared and cubic shocks are computed as:

$$
\begin{aligned}
& E_{t}^{H j}\left(\varepsilon_{H, t+1}\right)^{2}=\left(E_{t}^{H j} \varepsilon_{H, t+1}\right)^{2}+\operatorname{Var}_{t}^{H j}\left(\varepsilon_{H, t+1}\right) \\
& E_{t}^{H j}\left(\varepsilon_{H, t+1}\right)^{3}=\left(E_{t}^{H j} \varepsilon_{H, t+1}\right)^{3}+3\left(E_{t}^{H j} \varepsilon_{H, t+1}\right)\left(\operatorname{Var}_{t}^{H j}\left(\varepsilon_{H, t+1}\right)\right) \\
& E_{t}^{H j}\left(\varepsilon_{F, t+1}\right)^{2}=\left(E_{t}^{H j} \varepsilon_{F, t+1}\right)^{2}+\operatorname{Var}_{t}^{H j}\left(\varepsilon_{F, t+1}\right) \\
& E_{t}^{H j}\left(\varepsilon_{F, t+1}\right)^{3}=\left(E_{t}^{H j} \varepsilon_{F, t+1}\right)^{3}+3\left(E_{t}^{H j} \varepsilon_{F, t+1}\right)\left(\operatorname{Var}_{t}^{H j}\left(\varepsilon_{F, t+1}\right)\right)
\end{aligned}
$$

\section{First order solution}

We now describe the first-order solution of all variables other than the difference $z_{t}^{D}$ in portfolio shares. We leave the second-order solution to a Technical Appendix available on request. To a first order, the variables are linear functions of the state space:

$$
\begin{aligned}
q_{t}^{D}(1) & =\alpha_{q D}(0) S_{t}(1)+\alpha_{5, q D}(0) x_{t}^{D}(1) \\
q_{t}^{A}(1) & =\alpha_{q A}(0) S_{t}(1)+\alpha_{5, q A}(0) x_{t}^{D}(1) \\
c_{y t}^{A}(1) & =\alpha_{c A}(0) S_{t}(1)+\alpha_{5, c A}(0) x_{t}^{D}(1) \\
c_{y t}^{D}(1) & =\alpha_{c D}(0) S_{t}(1)+\alpha_{5, c D}(0) x_{t}^{D}(1) \\
k_{t+1}^{A}(1) & =\alpha_{k A}(0) S_{t}(1)+\alpha_{5, k A}(0) x_{t}^{D}(1) \\
k_{t+1}^{D}(1) & =\alpha_{k D}(0) S_{t}(1)+\alpha_{5, k D}(0) x_{t}^{D}(1)
\end{aligned}
$$

where:

$$
\begin{aligned}
S_{t}(1) & =\left[a_{t}^{D}(1), a_{t}^{A}(1), k_{t}^{D}(1), k_{t}^{A}(1)\right]^{\prime} \\
x_{t}^{D}(1) & =\varepsilon_{t+1}^{D}+\lambda\left(\tau_{t}^{D} / \tau\right)
\end{aligned}
$$

\section{Worldwide averages}

The solution in terms for the worldwide averages of consumption, equity prices and capital dynamics is computed by taking linear expansions of the equations (42)-(53). We then taking worldwide averages of the relations for the Home and Foreign country, before computing expectations using the results from signal ex- 
traction. We finally take the first-order component. The solution is given by:

$$
\begin{aligned}
c_{y t}^{A}(1)= & \frac{1}{\bar{c}}\left[1-(1-\bar{c})(1+\xi) \alpha_{2, k A}(0)\right] a_{t}^{A}(1)+ \\
& \frac{1-\bar{c}}{\bar{c}}\left[\frac{1-\omega}{1-\bar{c}}+\xi-(1+\xi) \alpha_{4, k A}(0)\right] k_{t}^{A}(1) \\
q_{t}^{A}(1)= & \xi \alpha_{2, k A}(0) a_{t}^{A}(1)+\xi\left(\alpha_{4, k A}(0)-1\right) k_{t}^{A}(1) \\
k_{t+1}^{A}(1)= & \alpha_{2, k A}(0) a_{t}^{A}(1)+\alpha_{4, k A}(0) k_{t}^{A}(1)
\end{aligned}
$$

where:

$$
\begin{aligned}
\alpha_{2, k A}(0) & =\frac{\gamma+\bar{c}(1-\gamma)\left(1-r_{q}\right) \rho}{\gamma(1+\xi)+\bar{c}(1-\gamma)\left[\left(1-r_{q}\right) \omega+r_{q} \xi\left(1-\alpha_{4, k A}(0)\right)+\xi\left(1-r_{q} \rho\right)\right]}>0 \\
r_{q} & =\frac{1-\delta}{(1-\omega) e^{-\omega k(0)}+(1-\delta)}
\end{aligned}
$$

and $\alpha_{4, k A}(0) \in(0,1)$ in $(58)$ is the root of the polynomial:

$$
\begin{aligned}
0= & -\left[1-\omega+\xi\left(1+\bar{c} \frac{1-\gamma}{\gamma}\right)\right]-\bar{c} \frac{1-\gamma}{\gamma} r_{q} \xi\left(\alpha_{4, k A}(0)\right)^{2} \\
& +\left[1+\bar{c} \frac{1-\gamma}{\gamma}\left(1-r_{q}\right) \omega+\left(1+\bar{c} \frac{1-\gamma}{\gamma}\left(1+r_{q}\right)\right) \xi\right] \alpha_{4, k A}(0)
\end{aligned}
$$

\section{Cross-country differences}

For cross-country differences in equations the approach is the same as for worldwide averages of equations: first take linear expansions of the equations (42)-(53). We then take the cross-country differences, and compute expectations using the results from signal extraction. We finally compute the first-order component. The results are:

$$
\begin{aligned}
q_{t}^{D}(1)= & \alpha_{1, q D}(0) a_{t}^{D}(1)+\alpha_{3, q D}(0) k_{t}^{D}(1)+\alpha_{5, q D}(0) x_{t}^{D}(1) \\
c_{y t}^{D}(1)= & a_{t}^{D}(1)+(1-\omega) k_{t}^{D}(1) \\
k_{t+1}^{D}(1)= & \frac{1}{\xi} \alpha_{1, q D}(0) a_{t}^{D}(1)+\left(1+\frac{1}{\xi} \alpha_{3, q D}(0)\right) k_{t}^{D}(1)+\frac{1}{\xi} \alpha_{5, q D}(0) x_{t}^{D}(1) \\
4 z_{t}^{A}(1)= & \left(\frac{1+\xi}{\xi} \alpha_{1, q D}(0)-z^{D}(0)\right) a_{t}^{D}(1) \\
& +\left(1+\frac{1+\xi}{\xi} \alpha_{3, q D}(0)-(1-\omega) z^{D}(0)\right) k_{t}^{D}(1)+\frac{1+\xi}{\xi} \alpha_{5, q D}(0) x_{t}^{D}
\end{aligned}
$$


where:

$$
\begin{aligned}
\alpha_{1, q D}(0) & =\frac{\left(1-r_{q}\right) \rho}{1-r_{q} \rho+\left[\left(1-r_{q}\right) \omega-r_{q} \alpha_{3, q D}(0)\right] \frac{1}{\xi}} \\
\alpha_{3, q D}(0) & =\frac{1}{2 r_{q}}\left[\left(1-r_{q}\right)(\xi+\omega)-\left[\left(1-r_{q}\right)^{2}(\xi+\omega)^{2}+4 r_{q}\left(1-r_{q}\right) \xi \omega\right]^{0.5}\right]<0 \\
\alpha_{5, q D}(0) & =\frac{1-r_{q}+r_{q} \alpha_{1, q D}(0)}{1+\left[\left(1-r_{q}\right) \omega-r_{q} \alpha_{3, q D}(0)\right] \frac{1}{\xi}} \frac{1}{1+2 \lambda^{2} \theta}
\end{aligned}
$$

The coefficient $\alpha_{5, q D}(0)$ in (59)-(62) is defined conditional on $\lambda$, which we still have to solve for.

To solve for $\lambda$, we first take the third-order component of the optimal portfolio condition for a Home investor (46) which can be written as:

$$
\begin{aligned}
& \gamma z_{H j, t}(1)\left[E_{t}\left(e r_{t+1}\right)^{2}\right](2) \\
= & {\left[E_{t}^{H j} e r_{t+1}\right](3)+\tau_{t}^{H j}(3)+(1-\gamma)\left[E_{t}^{H j} r_{t+1}^{A} e r_{t+1}\right](3) } \\
& +(1-\gamma) \tau\left[E_{t}^{H j} r_{t+1}^{A}\right](1)-\gamma \frac{2 z_{H j}(0)-1}{2}\left[E_{t}^{H j}\left(e r_{t+1}\right)^{2}\right](3) \\
& +\left[-\gamma(1+\gamma) \frac{z_{H j}(0)\left(1-z_{H j}(0)\right)}{2}+\frac{1}{6}-\frac{1-\gamma}{2} \frac{1+\gamma}{4}\right]\left[E_{t}^{H j}\left[e r_{t+1}\right]^{3}\right] \\
& +\frac{(1-\gamma)^{2}}{2}\left[E_{t}^{H j}\left(r_{t+1}^{A}\right)^{2} e r_{t+1}\right](3) \\
& -\gamma(1-\gamma) \frac{2 z_{H j}(0)-1}{2}\left[E_{t}^{H j} r_{t+1}^{A}\left(e r_{t+1}\right)^{2}\right]
\end{aligned}
$$

We can undertake similar steps for the optimal portfolio condition for a Foreign investor (47). Averaging across investors and taking the average of these relations for the Home and the Foreign country, we get

$$
\begin{aligned}
& 2 \gamma z_{t}^{A}(1)\left[E_{t}\left(e r_{t+1}\right)^{2}\right](2) \\
= & {\left[\bar{E}_{t}^{H} e r_{t+1}\right](3)+\left[\bar{E}_{t}^{F} e r_{t+1}\right](3)+\tau_{t}^{D}(3) } \\
& +(1-\gamma)\left[\left[\bar{E}_{t}^{H} r_{t+1}^{A} e r_{t+1}\right](3)+\left[\bar{E}_{t}^{F} r_{t+1}^{A} e r_{t+1}\right](3)\right] \\
& +\frac{(1-\gamma)^{2}}{2}\left[\left[\bar{E}_{t}^{H}\left(r_{t+1}^{A}\right)^{2} e r_{t+1}\right](3)+\left[\bar{E}_{t}^{F}\left(r_{t+1}^{A}\right)^{2} e r_{t+1}\right](3)\right] \\
& +(1-\gamma) \tau\left[\left[\bar{E}_{t}^{H} r_{t+1}^{A}\right](1)-\left[\bar{E}_{t}^{F} r_{t+1}^{A}\right](1)\right] \\
& -\gamma(1-\gamma)\left[\int \frac{2 z_{H j}(0)-1}{2}\left[E_{t}^{H j} r_{t+1}^{A}\left(e r_{t+1}\right)^{2}\right](3) d j\right] \\
& -\gamma\left[\int \frac{2 z_{F j}(0)-1}{2}\left[E_{t}^{F j} r_{t+1}^{A}\left(e r_{t+1}\right)^{2}\right](3) d j\right] \\
& {\left[\int \frac{2 z_{H j}(0)-1}{2}\left[E_{t}^{H j}\left(e r_{t+1}\right)^{2}\right](3) d j+\int \frac{2 z_{F j}(0)-1}{2}\left[E_{t}^{F j}\left(e r_{t+1}\right)^{2}\right](3) d j\right] }
\end{aligned}
$$


where $\bar{E}_{t}^{H}$ denotes the average expectation across Home investors, for instance: $\left[\bar{E}_{t}^{H} e r_{t+1}\right](3)=\int\left[E_{t}^{H j} e r_{t+1}\right](3) d j$. Similarly $\bar{E}_{t}^{F}$ denotes the average expectation across Foreign investors.

We can infer $\lambda$ by using (62) to substitute for $z_{t}^{A}(1)$ in (63). Both $z_{t}^{A}(1)$ in (62) and the terms on the right hand side of (63) (which are computed in the Technical Appendix available on request) depend on $x_{t}^{D}(1) . \tau_{t}^{D}(3)$ only enters in the second row of (63). Therefore (63) can only hold when $\varepsilon_{t+1}^{D}$ also enters (63) and in a way that is proportional to $x_{t}^{D}(1)$ when combined with the term in $\tau_{t}^{D}(3)$.

$\varepsilon_{t+1}^{D}$ only enters (63) through the term

$$
\left[\bar{E}_{t}^{H} e r_{t+1}\right](3)+\left[\bar{E}_{t}^{F} e r_{t+1}\right]
$$

and only through the linear component of $e r_{t+1}$, which is

$$
e r_{t+1}=-q_{t}^{D}+r_{q} q_{t+1}^{D}+\left(1-r_{q}\right)\left(a_{t+1}^{D}-\omega k_{t+1}^{D}\right)
$$

The only component of this that matters is the one that is proportional in $\varepsilon_{t+1}^{D}$. Abstracting from all the other terms we have

$$
\left[E_{t}^{H j} e r_{t+1}\right](3)=\left[r_{q} \alpha_{1, q D}(0)+\left(1-r_{q}\right)\right]\left[E_{t}^{H j}\left(\varepsilon_{H, t+1}-\varepsilon_{F, t+1}\right)\right]
$$

where $\left[E_{t}^{H j}\left(\varepsilon_{H, t+1}-\varepsilon_{F, t+1}\right)\right](3)$ is given by (54). We can undertake similar steps for a Foreign investors. Aggregating across individual investors, and again abstracting from terms other than $\varepsilon_{t+1}^{D}$, we obtain:

$$
\begin{aligned}
& {\left[\bar{E}_{t}^{H} e r_{t+1}\right](3)+\left[\bar{E}_{t}^{F} e r_{t+1}\right](3) } \\
= & {\left[r_{q} \alpha_{1, q D}(0)+\left(1-r_{q}\right)\right] \frac{2 \lambda^{2} \theta \sigma_{a}^{2}}{1+2 \lambda^{2} \theta}\left(\frac{1}{\sigma_{H, H}^{2}}+\frac{1}{\sigma_{H, F}^{2}}\right) \varepsilon_{t+1}^{D} }
\end{aligned}
$$

Focusing on the terms of interest on the right hand side of (63), we have

$$
\begin{aligned}
& {\left[\bar{E}_{t}^{H} e r_{t+1}\right](3)+\left[\bar{E}_{t}^{F} e r_{t+1}\right](3)+\tau_{t}^{D}(3)=} \\
& {\left[r_{q} \alpha_{1, q D}(0)+\left(1-r_{q}\right)\right] \frac{2 \lambda^{2} \theta \sigma_{a}^{2}}{1+2 \lambda^{2} \theta}\left(\frac{1}{\sigma_{H, H}^{2}}+\frac{1}{\sigma_{H, F}^{2}}\right) \varepsilon_{t+1}^{D}+\tau_{t}^{D}(3)}
\end{aligned}
$$

The ratio between the coefficient on $\varepsilon_{t+1}^{D}$ and the coefficient on $\tau_{t}^{D}(3)$ must be the same as in $x_{t}^{D}(1)$, implying:

$$
\left[1-r_{q}+r_{q} \alpha_{1, q D}(0)\right] \frac{\sigma_{H, H}^{2}+\sigma_{H, F}^{2}}{\sigma_{H, H}^{2} \sigma_{H, F}^{2}} \lambda=\frac{1+2 \lambda^{2} \theta}{2 \lambda^{2} \theta} \frac{\tau}{\sigma_{a}^{2}}
$$


The left-hand side of (64) is an increasing linear function of $\lambda$ which is flatter the higher the variance of the errors of the private signals. The right-hand side of (64) is decreasing function of $\lambda$ that is infinite when $\lambda \rightarrow 0$ and converges to $\tau / \sigma_{a}^{2}$ when $\lambda \rightarrow \infty$. (64) therefore gives an implicit solution for $\lambda$. Combining it with (59)-(62) gives the first-order solution for the model.

After computing the terms on the right hand side of (63), done in the Technical Appendix, it simplifies to

$$
\begin{aligned}
z_{t}^{A}(1)= & \frac{\left[\bar{E}_{t}^{A} e r_{t+1}\right](3)}{\gamma\left[E_{t}\left(e r_{t+1}\right)^{2}\right](2)}+\frac{\tau_{t}^{D}(3)}{2 \gamma\left[E_{t}\left(e r_{t+1}\right)^{2}\right](2)} \\
& +\frac{1-\gamma}{\gamma} \frac{\left[\operatorname{var}_{t}\left(r_{H t+1}\right)\right](3)-\left[\operatorname{var}_{t}\left(r_{F t+1}\right)\right](3)}{2\left[E_{t}\left(e r_{t+1}\right)^{2}\right](2)}
\end{aligned}
$$

\section{Portfolio difference}

\section{Zero order solution}

We solve for $z^{D}(0)=z_{H}(0)-z_{F}(0)$ by taking the second-order component of the optimal portfolio condition for a Home investor (46) which can be written as:

$$
z_{H j}(0)=\frac{1}{2}+\frac{\left[E_{t}^{H j} e r_{t+1}\right](2)+\tau}{\gamma\left[E_{t}^{H j}\left(e r_{t+1}\right)^{2}\right](2)}+\frac{1-\gamma}{\gamma} \frac{\left[E_{t}^{H j} e r_{t+1} r_{t+1}^{A}\right](2)}{\left[E_{t}^{H j}\left(e r_{t+1}\right)^{2}\right](2)}
$$

We can undertake similar steps for the optimal portfolio condition for a Foreign investor (47). After summing across investors and taking the difference between these relations in the Home and the Foreign country, we get

$$
\begin{aligned}
z^{D}(0)= & \frac{2 \tau}{\gamma\left[E_{t}\left(e r_{t+1}\right)^{2}\right](2)}+\frac{\left[\bar{E}_{t}^{H} e r_{t+1}\right](2)-\left[\bar{E}_{t}^{F} e r_{t+1}\right](2)}{\gamma\left[E_{t}\left(e r_{t+1}\right)^{2}\right](2)} \\
& +(1-\gamma) \frac{\left[\bar{E}_{t}^{H} e r_{t+1} r_{t+1}^{A}\right](2)-\left[\bar{E}_{t}^{F} e r_{t+1} r_{t+1}^{A}\right](2)}{\gamma\left[E_{t}\left(e r_{t+1}\right)^{2}\right](2)}
\end{aligned}
$$

We can show that $\left[\bar{E}_{t}^{H} e r_{t+1} r_{t+1}^{A}\right](2)=\left[\bar{E}_{t}^{F} e r_{t+1} r_{t+1}^{A}\right](2)=0$ and $\left[\bar{E}_{t}^{H} e r_{t+1}\right](2)=$ $\left[\bar{E}_{t}^{F} e r_{t+1}\right](2)$. In addition:

$$
\left[E_{t}^{H j}\left(e r_{t+1}\right)^{2}\right](2)=2 \sigma_{a}^{2}\left(1-r_{q}+r_{q} \alpha_{1, q D}(0)\right)^{2} \Gamma
$$


where $\Gamma \in[0,1]$ is an increasing function of $\lambda$ that converges to one when private signals are infinitely noisy $(\lambda \rightarrow \infty)$ :

$$
\Gamma=1-\left[1-\left(\frac{r_{q}}{1+\left[\left(1-r_{q}\right) \omega-r_{q} \alpha_{3, q D}(0)\right] \frac{1}{\xi}}\right)^{2}\right] \frac{1}{1+2 \lambda^{2} \theta}
$$

The zero-order portfolio difference is then:

$$
z^{D}(0)=\frac{2 \tau}{\gamma\left[E_{t}\left(e r_{t+1}\right)^{2}\right](2)}=\frac{\tau}{\gamma \sigma_{a}^{2}} \frac{1}{\left(1-r_{q}+r_{q} \alpha_{1, q D}(0)\right)^{2}} \frac{1}{\Gamma}
$$

\section{First-order solution}

The first-order component of the difference in portfolio shares is solved by taking the average over Home investors of the third-order component of the optimal portfolio condition (46) and substracting the average across Foreign investors of the third-order component of the optimal portfolio condition (47). This gives

$$
\begin{aligned}
& \gamma z_{t}^{D}(1)\left[E_{t}\left(e r_{t+1}\right)^{2}\right](2) \\
& =\left[\bar{E}_{t}^{H} e r_{t+1}\right](3)-\left[\bar{E}_{t}^{F} e r_{t+1}\right](3) \\
& +(1-\gamma)\left[\left[\bar{E}_{t}^{H} r_{t+1}^{A} e r_{t+1}\right](3)-\left[\bar{E}_{t}^{F} r_{t+1}^{A} e r_{t+1}\right](3)\right] \\
& +(1-\gamma) \tau\left[\left[\bar{E}_{t}^{H} r_{t+1}^{A}\right](1)+\left[\bar{E}_{t}^{F} r_{t+1}^{A}\right](1)\right] \\
& -\gamma\left[\begin{array}{c}
\int \frac{2 z_{H j}(0)-1}{2}\left[E_{t}^{H j}\left(e r_{t+1}\right)^{2}\right](3) d j \\
-\int \frac{2 z_{F j}(0)-1}{2}\left[E_{t}^{F j}\left(e r_{t+1}\right)^{2}\right](3) d j
\end{array}\right] \\
& +\frac{(1-\gamma)^{2}}{2}\left[\left[\bar{E}_{t}^{H}\left(r_{t+1}^{A}\right)^{2} e r_{t+1}\right](3)-\left[\bar{E}_{t}^{F}\left(r_{t+1}^{A}\right)^{2} e r_{t+1}\right](3)\right] \\
& -\gamma(1-\gamma)\left[\begin{array}{c}
\int \frac{2 z_{H j}(0)-1}{2}\left[E_{t}^{H j} r_{t+1}^{A}\left(e r_{t+1}\right)^{2}\right](3) d j \\
-\int \frac{2 z_{F j}(0)-1}{2}\left[E_{t}^{F j} r_{t+1}^{A}\left(e r_{t+1}\right)^{2}\right](3) d j
\end{array}\right]
\end{aligned}
$$

Using the results for both the first and second-order solution of all variables other than $z_{t}^{D}$, we compute the various terms on the right hand side of this expression (the details are in the Technical Appendix available on request). This gives

$$
z_{t}^{D}(1)=\frac{\left[\bar{E}_{t}^{H} e r_{t+1}\right](3)-\left[\bar{E}_{t}^{F} e r_{t+1}\right](3)}{\gamma\left[E_{t}\left(e r_{t+1}\right)^{2}\right](2)}-z^{D}(0) \frac{\left[E_{t}\left(e r_{t+1}\right)^{2}\right](3)}{\left[E_{t}\left(e r_{t+1}\right)^{2}\right](2)}
$$

where $\left[\bar{E}_{t}^{H} e r_{t+1}\right](3)-\left[\bar{E}_{t}^{F} e r_{t+1}\right](3)$ and $\left[E_{t}\left(e r_{t+1}\right)^{2}\right]=\left[\operatorname{var}_{t}\left(e r_{t+1}\right)\right](3)$ are given by (33) and (34). 


\section{E Balance of Payments Accounting}

\section{Saving and investment}

Saving is equal to income minus consumption. National savings in the Home and Foreign countries are, net of depreciation of capital, are

$$
\begin{aligned}
S_{t}^{H}= & \int\left(W_{H, t}-C_{y, t}^{H j}\right) d j \\
& -\int\left[z_{H j, t-1} \frac{Q_{H, t}}{Q_{H, t-1}}+\left(1-z_{H j, t-1}\right) \frac{Q_{F, t}}{Q_{F, t-1}}\right]\left(W_{H, t-1}-C_{y, t-1}^{H j}\right) d j \\
S_{t}^{F}= & \int\left(W_{F, t}-C_{y, t}^{F j}\right) d j \\
& -\int\left[z_{F j, t-1} \frac{Q_{H, t}}{Q_{H, t-1}}+\left(1-z_{F j, t-1}\right) \frac{Q_{F, t}}{Q_{F, t-1}}\right]\left(W_{F, t-1}-C_{y, t-1}^{F j}\right) d j
\end{aligned}
$$

The first-order components of savings are

$$
\begin{aligned}
s_{t}^{H}(1)= & \frac{1}{1-\bar{c}}\left[\Delta a_{H, t}(1)+(1-\omega) \Delta k_{H, t}(1)\right] \\
& -\frac{\bar{c}}{1-\bar{c}} \Delta c_{y, t}^{H}(1)-\Delta q_{t}^{A}(1)-\frac{z^{D}(0)}{2} \Delta q_{t}^{D}(1) \\
s_{t}^{F}(1)= & \frac{1}{1-\bar{c}}\left[\Delta a_{F, t}(1)+(1-\omega) \Delta k_{F, t}(1)\right] \\
& -\frac{\bar{c}}{1-\bar{c}} \Delta c_{y, t}^{F}(1)-\Delta q_{t}^{A}(1)+\frac{z^{D}(0)}{2} \Delta q_{t}^{D}(1)
\end{aligned}
$$

where $s_{t}^{i}(1)$ is scaled by the steady state wealth: $s_{t}^{i}(1)=S_{t}^{i}(1) /(W(0)(1-\bar{c}))$. In addition for a variable $g: \Delta g_{t}(1)=g_{t}(1)-g_{t-1}(1)$. Using (56) and (60), the first-order component of consumption is

$$
\begin{aligned}
\Delta c_{y, t}^{H}(1) & =\Delta c_{y, t}^{A}(1)+\frac{1}{2} \Delta c_{y, t}^{D}(1) \\
& =\alpha_{2, c A}(0) \Delta a_{t}^{A}(1)+\alpha_{4, c A}(0) \Delta k_{t}^{A}(1)+\frac{1}{2}\left[\Delta a_{t}^{D}(1)+(1-\omega) \Delta k_{t}^{D}(1)\right]
\end{aligned}
$$

Savings in a specific country are then affected by information dispersion only through relative equity prices:

$$
\begin{aligned}
s_{t}^{H}(1) & =\alpha_{s H} \Delta S_{t}(1)-\frac{z^{D}(0)}{2} \Delta q_{t}^{D}(1) \\
s_{t}^{F}(1) & =\alpha_{s F} \Delta S_{t}(1)+\frac{z^{D}(0)}{2} \Delta q_{t}^{D}(1) \\
s_{t}^{D}(1) & =\Delta a_{t}^{D}(1)+(1-\omega) \Delta k_{t}^{D}(1)-z^{D}(0) \Delta q_{t}^{D}(1)
\end{aligned}
$$


where $s_{t}^{D}(1)=s_{t}^{H}(1)-s_{t}^{F}(1)$.

Investment is also defined net of depreciation:

$$
I_{i, t}^{n e t}=I_{i, t}-\delta K_{i, t-1}=K_{i, t}-K_{i, t-1} \quad i=H, F
$$

The first-order component of investment, scaled by steady-state wealth, is then:

$$
i_{t}^{D, \text { net }}(1)=\frac{I_{t}^{H, \text { net }}(1)-I_{t}^{F, \text { net }}(1)}{e^{w(0)}(1-\bar{c})}=\Delta k_{t+1}^{D}(1)=\frac{1}{\xi} q_{t}^{D}(1)
$$

where we used (5).

\section{Capital flows}

The passive portfolio share combines the steady-state holdings of quantities of assets with the actual asset prices. For Home investors, we write:

$$
z_{H, t}^{p}=\frac{z_{H}(0) e^{q_{H, t}}}{z_{H}(0) e^{q_{H, t}}+\left(1-z_{H}(0)\right) e^{q_{F, t}}}
$$

The first-order component of the passive portfolio share is the same for all investors and reflects the relative asset price between Home and Foreign equity:

$$
z_{t}^{p}(1)=z_{H}(0)\left(1-z_{H}(0)\right) q_{t}^{D}(1)
$$

Using the difference between the first-order components of (48) and (49) we get:

$$
\Delta z_{t}^{A}(1)-\Delta z_{t}^{p}(1)=\frac{1}{4}\left[i_{t}^{D, n e t}(1)-z^{D}(0) s_{t}^{D}(1)\right]
$$

Gross capital outflows and inflows reflect the changes in the value of crossborder asset holdings, evaluated at current prices:

$$
\begin{aligned}
\text { OUTFLOW } S_{t}= & \int\left(1-z_{H j, t}\right)\left(W_{H, t}-C_{y, t}^{H j}\right) d j \\
& -\frac{Q_{F, t}}{Q_{F, t-1}} \int\left(1-z_{H j, t-1}\right)\left(W_{H, t-1}-C_{y, t-1}^{H j}\right) d j \\
\text { INFLOW } S_{t}= & \int z_{F j, t}\left(W_{F, t}-C_{y, t}^{F j}\right) d j \\
& -\frac{Q_{H, t}}{Q_{H, t-1}} \int z_{F j, t-1}\left(W_{F, t-1}-C_{y, t-1}^{F j}\right) d j
\end{aligned}
$$


The first-order component of outflows, scaled by steady-state wealth $W(0)(1-\bar{c})$, is:

$$
\begin{aligned}
\text { outflows }_{t}(1)= & -\left(1-z_{H}(0)\right) \Delta q_{F, t}(1)-\Delta z_{H, t}(1) \\
& +\frac{1-z_{H}(0)}{1-\bar{c}}\left[\Delta a_{H, t}(1)+(1-\omega) \Delta k_{H, t}(1)-\bar{c} \Delta c_{y, t}^{H}(1)\right] \\
= & \left(1-z_{H}(0)\right) s_{t}^{H}(1)-\left[\Delta z_{t}^{A}(1)-\Delta z_{t}^{p}(1)\right]-\frac{1}{2} \Delta z_{t}^{D}(1) \\
= & \left(1-z_{H}(0)\right) s_{t}^{H}(1)+\frac{z^{D}(0)}{2} \frac{\Delta\left[E_{t}\left(e r_{t+1}\right)^{2}\right](3)}{\left[E_{t}\left(e r_{t+1}\right)^{2}\right](2)} \\
& -\frac{\Delta \bar{E}_{t} e r_{t+1}(3)^{I S}}{\gamma\left[E_{t}\left(e r_{t+1}\right)^{2}\right](2)}-\frac{1}{2} \frac{\Delta\left[\bar{E}_{t}^{H} e r_{t+1}\right](3)-\Delta\left[\bar{E}_{t}^{F} e r_{t+1}\right](3)}{\gamma\left[E_{t}\left(e r_{t+1}\right)^{2}\right](2)}
\end{aligned}
$$

where:

$$
\Delta \bar{E}_{t} e r_{t+1}(3)^{I S}=\frac{\gamma\left[E_{t}\left(e r_{t+1}\right)^{2}\right](2)}{4}\left[i_{t}^{D}(1)-z^{D}(0) s_{t}^{D}(1)\right]
$$

Similarly, inflows are:

$$
\begin{aligned}
\text { inflows }_{t}(1)= & z_{F}(0) s_{t}^{F}(1)+\left[\Delta z_{t}^{A}(1)-\Delta z_{t}^{p}(1)\right]-\frac{1}{2} \Delta z_{t}^{D}(1) \\
= & \left(1-z_{H}(0)\right) s_{t}^{F}(1)+\frac{z^{D}(0)}{2} \frac{\Delta\left[E_{t}\left(e r_{t+1}\right)^{2}\right](3)}{\left[E_{t}\left(e r_{t+1}\right)^{2}\right](2)} \\
& +\frac{\Delta \bar{E}_{t} e r_{t+1}(3)^{I S}}{\gamma\left[E_{t}\left(e r_{t+1}\right)^{2}\right](2)}-\frac{1}{2} \frac{\Delta\left[\bar{E}_{t}^{H} e r_{t+1}\right](3)-\Delta\left[\bar{E}_{t}^{F} e r_{t+1}\right](3)}{\gamma\left[E_{t}\left(e r_{t+1}\right)^{2}\right](2)}
\end{aligned}
$$

\section{F Data Appendix}

Here follows a description of the data used in section 5 .

Capital Flows: Quarterly data on capital flows are obtained from the IMF International Financial Statistics (IFS). Capital outflows are computed as the sum of direct investment abroad, portfolio investment assets and other investment assets. Capital inflows are the sum of direct investment liabilities, portfolio investment liabilities and other investment liabilities. Net capital flows is alternatively computed as capital outflows minus inflows or the current account (also from the IFS). All capital flow data are converted from dollars to the local currency by multiplying with the quarterly exchange rate (IFS), and are scaled by the gross domestic

product (IFS, seasonally adjusted). When computing annual net and gross capital 
flows we first aggregate over the quarterly data before dividing by annual GDP. These data are used in the VAR analysis and Granger causality tests.

interest rates: We use the Treasury bill rate from the IFS, with the exception of France, where the short-term rate from the OECD Economic Outlook is used. The latter is very close to the Treasury bill rate from the IFS, but that series is not available after Q3, 2004. Annual interest rates are computed by averaging over the quarterly data. These data are used in the VAR analysis and Granger causality tests.

real GDP growth: Quarterly real GDP growth is computed as the change in the log seasonally adjusted GDP volume from the IFS. Annual GDP growth is based on annual GDP volume data from the IFS. These data are used in the VAR analysis and Granger causality tests.

real investment growth: Annual investment growth is computed as the growth rate of annual total gross fixed capital formation (volume) from the OECD Economic Outlook. These data are used in the calibration of the model, which matches the standard deviation of average real investment growth relative to annual real GDP growth, with the latter also computed with OECD Economic Outlook data. inflation: Quarterly inflation is computed as the quarterly change in the log CPI from the IFS. Annual inflation is computed after first averaging the price indices for each quarter. These data are used in the VAR analysis and Granger causality tests.

budget deficit: We use quarterly data on government net lending as a percentage of GDP, from the OECD Economic Outlook, as a measure of the budget deficit. These data are not available for Germany and France, for which we therefore omit the budget deficit from the quarterly VAR analysis. Annual data are available from the OECD Economic Outlook for all countries and are used in the annual VAR analysis and Granger causality test.

profit rate: The annual profit rate is computed as nominal GDP minus employee compensation, divided by the value of the capital stock. The latter is computed as the product of the volume of the capital stock for the total economy and the deflator of total gross fixed capital formation. All data are from the OECD Economic Outlook. These data are used in the Granger causality tests. 
labor share: The labor share is computed as the ratio of total employee compensation to nominal GDP, both from the OECD Economic Outlook. These data are used for the calibration of the model, which matches the average labor share in the data.

Solow Residual: Annual Solow residuals are computed using data on GDP volume, total employment and the volume of the capital stock for the total economy, all from the OECD Economic Outlook. The log Solow residual is then computed as $a_{i t}=y_{i t}-\omega n_{i t}-(1-\omega) k_{i t}$, where $y_{i t}, n_{i t}$ and $k_{i t}$ are respectively log GDP, log employment and log capital stock and $\omega$ is the estimated labor share. These data are used to compute the persistence of $a_{i t}$ in the calibration of the model. 


\section{References}

[1] Albuquerque, Rui, Gregory H. Bauer and Martin Schneider (2008), "Global Private Information in International Equity Markets," Journal of Financial Economics, forthcoming.

[2] Albuquerque, Rui, Gregory H. Bauer and Martin Schneider (2007), "International Equity Flows and Returns: A Quantitative Equilibrium Approach," Review of Economic Studies 74(1), 1-30.

[3] Bacchetta, Philippe and Eric van Wincoop (2004), "A Scapegoat Model of Exchange Rate Fluctuations," American Economic Review, Papers and Proceedings, May 2004, 114-118.

[4] Bacchetta, Philippe and Eric van Wincoop (2006), "Can Information Heterogeneity Explain the Exchange Rate Determination Puzzle? ", American Economic Review 96(3), 552-576.

[5] Bacchetta, Philippe and Eric van Wincoop (2008), "Higher Order Expectations in Asset Pricing," Journal of Money, Credit and Banking 40(5), 837-866.

[6] Backus, David K., Patrick J. Kehoe and Finn E. Kydland (1992), "International Real Business Cycles," Journal of Political Economy 100(4), 745-775.

[7] Bae, Kee-Hong, Hongping Tan and Rene M. Stulz (2007), "Do Local Analysts Know More? A Cross-Country Study of Performance of Local Analysts and Foreign Analysts," Journal of Financial Economics, forthcoming.

[8] Beaudry, Paul and Franck Portier (2003), Stock Prices, News and Economic Fluctuations, NBER working paper 10548.

[9] Brennan, Michael J. and H. Henry Cao (1997), "International Portfolio Investment Flows," The Journal of Finance 52, 1851-1880.

[10] Devereux, Michael B. and Charles Engel (2006), Expectations and Exchange Rate Policy, NBER working paper 12213.

[11] Devereux, Michael B. and Alan Sutherland (2007), "Country Portfolio Dynamics," working paper, University of British Columbia. 
[12] Dow, James and Gary Gorton (1995), "Profitable Informed Trading in a Simple General Equilibrium Model of Asset Pricing," Journal of Economic Theory $67,327-369$.

[13] Evans, Martin D. D., and Richard K. Lyons (2002), "Order Flow and Exchange Rate Dynamics," Journal of Political Economy 110, 170-180.

[14] Evans, Martin D.D. and Viktoria Hnatkovska (2008), "Solving General Equilibrium Models with Incomplete Markets and Many Financial Assets," working paper, Georgetown University.

[15] Fidora, Michael, Marcel Fratzscher and Christian Thimann (2007), "Home Bias in Global Bond and Equity Markets: The Role of Real Exchange Rate Volatility," Journal of International Money and Finance 26, 631-655.

[16] Gehrig, Thomas (1993), "An Information Based Explanation of the Domestic Bias in International Equity Investment, "Scandinavian Journal of Economics 95(1), 97-109.

[17] Gennotte, Gerard and Hayne Leland (1990), "Market Liquidity, Hedging and Crashes," The American Economic Review 80(5), 999-1021.

[18] Jaimovich, Nir and Sergio Rebelo (2008), Can news About the Future Drive the Business Cycle?, working paper, Northwestern University.

[19] Jorion, Philippe, and Will Goetzmann (1999), "Global Stock Markets in the Twentieth Century," Journal of Finance 54, 953-980.

[20] Leuz, Christian, Karl V. Lins, and Francis E. Warnock (2008), "Do Foreigners Invest Less in Poorly Governed Firms?, "Review of Financial Studies, forthcoming.

[21] Lorenzoni, Guido (2007), News Shocks and Optimal Monetary Policy, NBER Working paper 12898.

[22] Shiller, Robert J., Fumiko Kon-Ya and Yoshiro Tstsui (1996), "Why did the Nikkei Crash? Expanding the Scope of Expectations Data Collection," Review of Economics and Statistics 78(1), 156-164. 
[23] Spiegel, M. and A. Subrahmanyam (1992), "Informed Speculation and Hedging in a Noncompetitive Securities Market," The Review of Financial Studies 5, 307-329.

[24] Tille, Cedric and Eric van Wincoop (2008), "International Capital Flows," CEPR Discussion paper 6705.

[25] Veldkamp, Laura and Stijn van Nieuwerburgh (2008), "Information Immobility and the Home Bias Puzzle, "Journal of Finance, forthcoming.

[26] Wang, Jiang (1994), "A Model of Competitive Stock Trading Volume," Journal of Political Economy 102, 127-168. 


\section{Figure 1 Modeling Contribution}

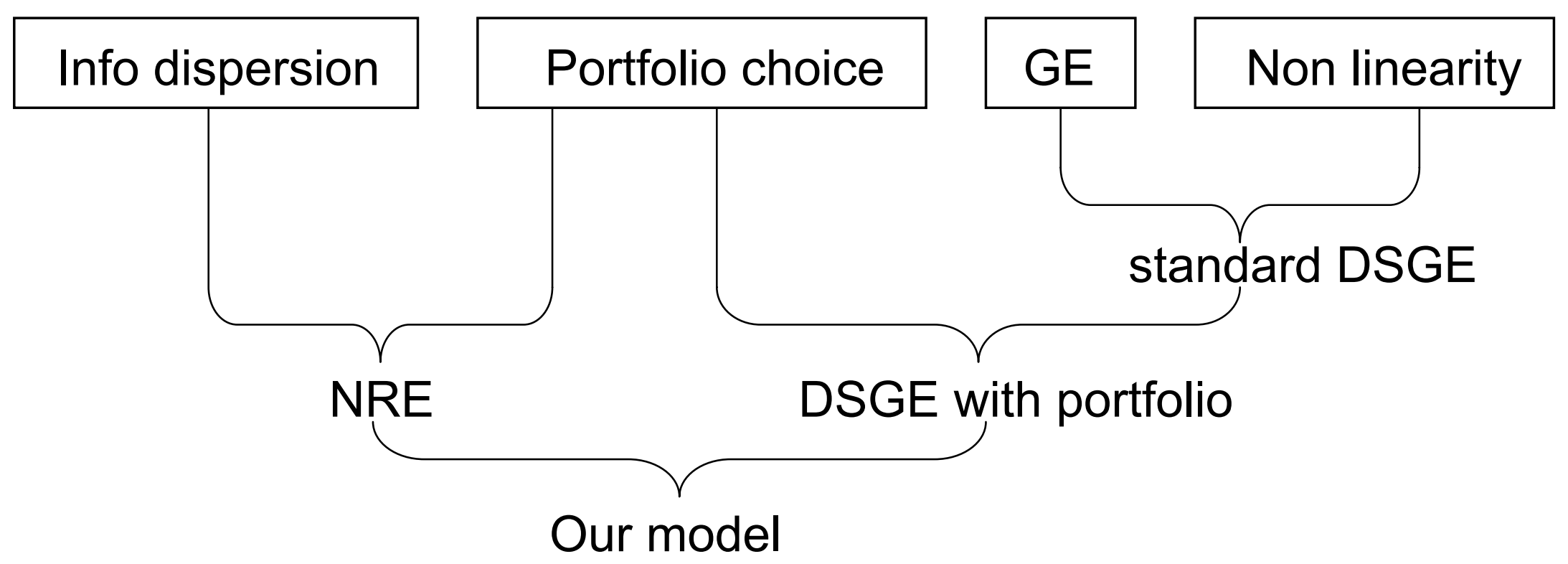




\section{Figure 2 Role of Information Dispersion}
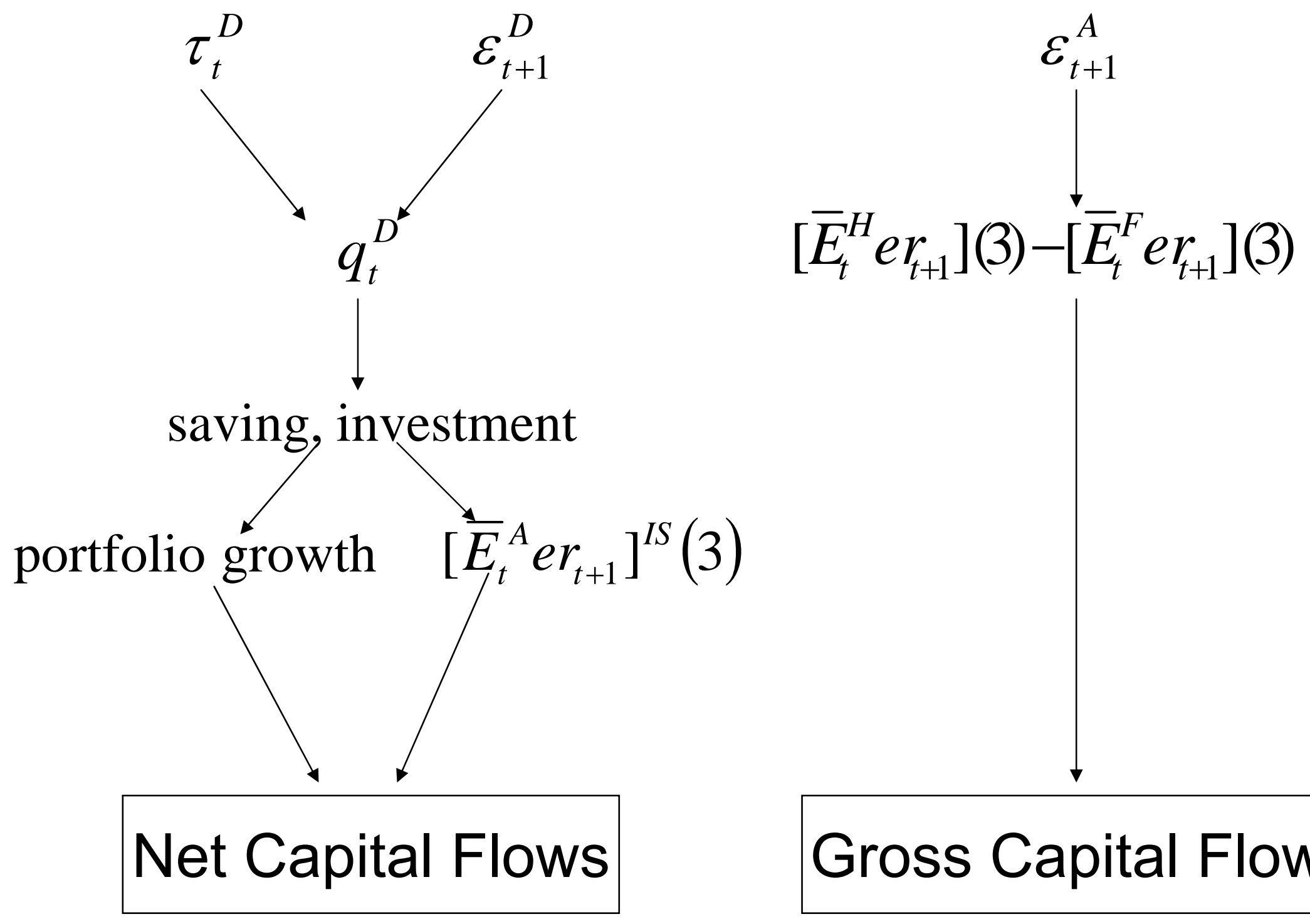

Gross Capital Flows 


\section{Figure 3 Results From Model Simulation*}
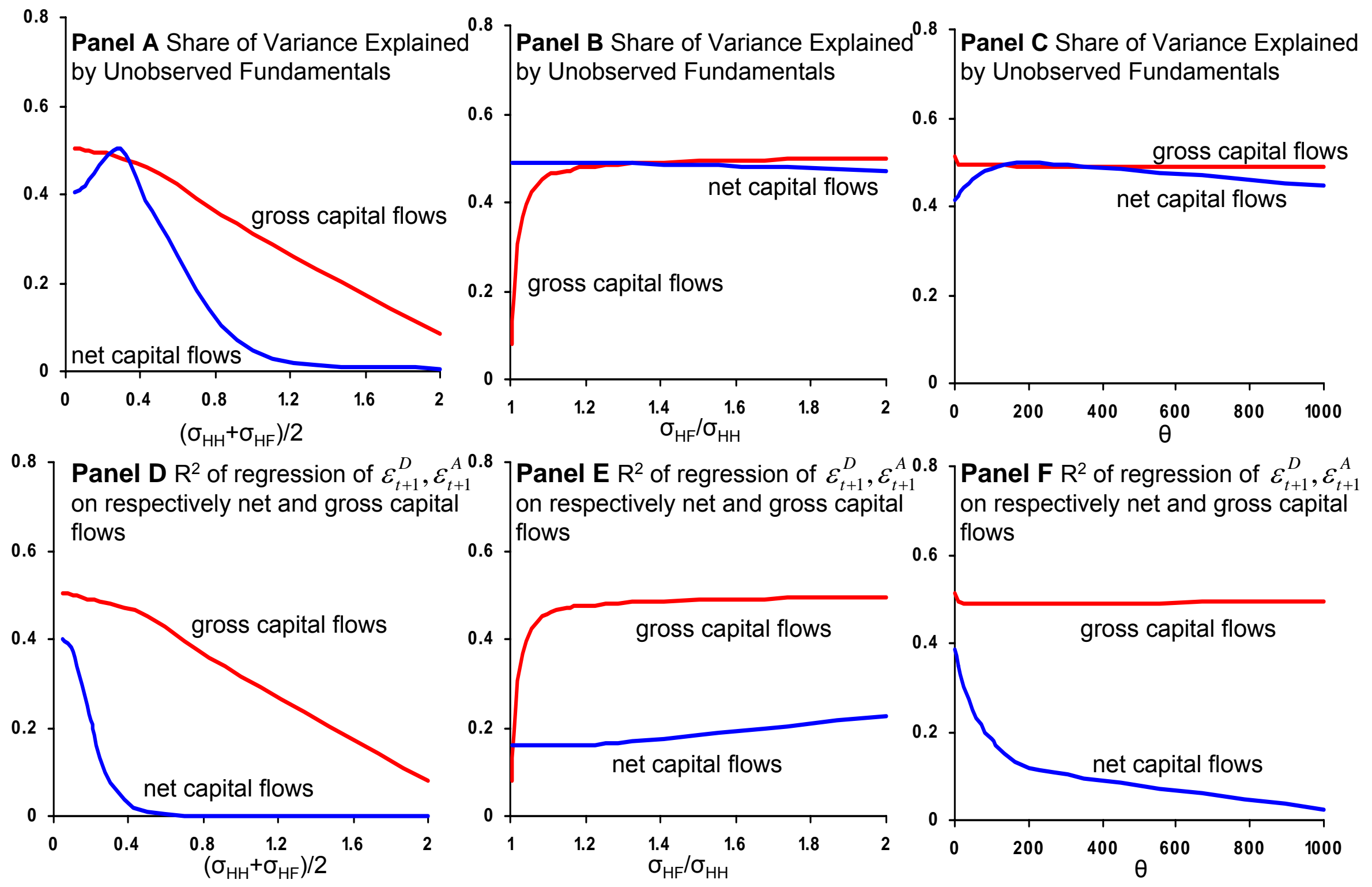

*Gross Capital flows=capital outflows+capital infows; Net capital flows=capital outflows-capital inflows. Results are based on a simulation of the model over 100,000 periods. 


\section{Table 1. Percentage Variance of Gross and Net Capital Flows Accounted for by Macro Fundamentals: Quarterly Data, 1977(1)-2007(2)}

Capital flow measure
Horizon
United States
Japan




\section{Table 2. Percentage Variance of Gross and Net Capital Flows Accounted for by Macro Fundamentals: Annual Data, 1977-2006}

\begin{tabular}{|c|c|c|c|c|c|c|}
\hline Capital flow measure & & s+Inflows & DP) & & Account ( & PP) \\
\hline Horizon & 1 year & 2 years & 3 years & 1 year & 2 years & 3 years \\
\hline United States & 33 & 38 & 47 & 53 & 63 & 69 \\
\hline Japan & 10 & 20 & 32 & 51 & 55 & 56 \\
\hline Canada & 35 & 39 & 40 & 44 & 61 & 68 \\
\hline United Kingdom & 10 & 10 & 17 & 10 & 25 & 33 \\
\hline Germany & 25 & 29 & 34 & 28 & 56 & 65 \\
\hline France & 10 & 7 & 7 & 16 & 22 & 26 \\
\hline Average & 21 & 24 & 30 & 34 & 47 & 53 \\
\hline $\begin{array}{l}\text { Notes. The table reports } t \\
\text { GDP growth, the inflatio } \\
\text { capital flows in the first } r \\
\text { with the ordering of the } \\
\text { inflows and outflows), th } \\
\text { For the VARs including } \\
\text { minus a GDP-weighted a } \\
\text { 2006, with one lag of eac } \\
\text { to the variance of gross a }\end{array}$ & $\begin{array}{l}\text { ribution } \\
\text { he T-bill } \\
\text { he table } \\
\text { s as in th } \\
\text { o-variabl } \\
\text { tal flows } \\
\text { of that in } \\
\text { ble. The } \\
\text { capital flc }\end{array}$ & $\begin{array}{l}\text { cro variable } \\
\text { the budget } \\
\text { ction of GD } \\
\text { ious senten } \\
\text { computed } \\
\text { urrent acco } \\
\text { ther countri } \\
\text { eports the } t \\
\text { ver } 1,2 \text { and }\end{array}$ & $\begin{array}{l}\text { gross and } \mathrm{I} \\
\text { t as a fract } \\
\text { Identificat } \\
\text { or VARs i } \\
\text { DP-weigh } \\
\text { the macro } \\
\text { he results } \\
\text { contributio } \\
\text { ar horizon }\end{array}$ & $\begin{array}{l}\text { pital flow } \\
\text { GDP an } \\
\text { achieved } \\
\text { ng gross } \\
\text { erage of } \\
\text { bles equa } \\
\text { sed on } 30 \\
\text { nnovation }\end{array}$ & $\begin{array}{l}\text { based on a } \\
\text { neasure of } \\
\text { the Choles } \\
\text { l flows (sur } \\
\text { x countries } \\
\text { at variable } \\
\text { al observat } \\
\text { ll four macr }\end{array}$ & $\begin{array}{l}\text { of real } \\
\text { or net } \\
\text { compositio } \\
\text { capital } \\
\text { e sample. } \\
\text { e country } \\
\text { from } 1977 \\
\text { idamentals }\end{array}$ \\
\hline
\end{tabular}




\section{Table 3. Granger Causality Test of "World Profit Rate” by Capital Inflows+Outflows (\% GDP): Annual Data, 1977-2006}

\begin{tabular}{|c|c|c|c|}
\hline \multirow[b]{2}{*}{ Control variables } & \multirow[t]{2}{*}{ Bivariate } & \multicolumn{2}{|c|}{ Multivariate } \\
\hline & & $\begin{array}{c}\text { World GDP } \\
\text { Growth, } \\
\text { interest rate, } \\
\text { inflation }\end{array}$ & $\begin{array}{l}\text { World GDP } \\
\text { Growth, interest } \\
\text { rate, inflation, } \\
\text { budget deficit }\end{array}$ \\
\hline United States & - & 2.9 & - \\
\hline Japan & - & - & - \\
\hline Canada & 0.1 & 0.2 & 4.5 \\
\hline United Kingdom & 2.3 & 1.3 & 6.9 \\
\hline Germany & 2.9 & 0.0 & 4.7 \\
\hline France & 1.7 & 0.4 & 9.4 \\
\hline \# significant at $10 \%$ & 4 & 5 & 4 \\
\hline
\end{tabular}

Notes. The table reports p-values (in \%) from the F-test that the sum of inflows and outflows (as a fraction of GDP) does not Granger cause the world profit rate. A value of 2.5 for example indicates that the null of no Granger causality is rejected at the $2.5 \%$ level. The wor1d profit rate is defined as a GDP-weighted average of profit rates of all 6 countries. The profit rate is equal to GDP minus employee compensation, divided by the capital stock. The table only reports p-values for countries where there is significance at the $10 \%$ level or better. The multivariate Granger Causality test results in columns 3 and 4 introduce GDP weighted averages of respectively 3 and 4 control variables. In column 3 they are real GDP growth, the Tbill rate and the CPI inflation rate. In column 4 the budget deficit as a share of GDP is an additional control variable. The results are based on annual data from 1977 to 2006 with one lag for all variables. 


\section{Table 4. Granger Causality Test of “Relative Profit Rate” by Net Capital Flows: Annual Data, 1977-2006.}

Control variables

Capital flow measure

United States

Japan

Canada

United Kingdom

Germany

France

\# significant at $10 \%$

\section{Bivariate}

\author{
Relative GDP growth, \\ interest rate, inflation \\ CA \\ outflows- \\ inflows
}

outflows-

inflows

$-$

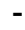

1.3

1.6

1.0
Multivariate

Relative GDP growth, interest rate, inflation, budget deficit

CA outflowsinflows
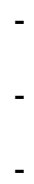

2.8

1

Notes. The table reports p-values (in \%) from the F-test that net capital flows do not Granger cause the relative profit rate. A value of 2.5 for example indicates that the null of no Granger causality is rejected at the $2.5 \%$ level. The relative profit rate is defined as the profit rate in a country relative to a GDP-weighted average of that in the other countries. The profit rate is equal to GDP minus employee compensation, divided by the capital stock. The table only reports p-values for countries where there is significance at the $10 \%$ level or better. The multivariate Granger Causality test results in columns 3 and 4 introduce respectively 3 and 4 control variables. In column 3 they are real GDP growth, the T-bill rate and the CPI inflation rate. In column 4 the budget deficit as a share of GDP is an additional control variable. All control variables are relative to a GDP weighted average of that in the other countries. The results are based on annual data from 1977 to 2006 with one lag for all variables. 